\title{
Dihydrofolate reductase, thymidylate synthase, and serine hydroxy methyltransferase: successful targets against some infectious diseases
}

\author{
Hina Shamshad ${ }^{1}$ (D) $\cdot$ Rowaida Bakri $^{2} \cdot$ Agha Zeeshan Mirza $^{3}$ (D)
}

Received: 21 August 2021 / Accepted: 15 February 2022 / Published online: 7 March 2022

(c) The Author(s), under exclusive licence to Springer Nature B.V. 2022

\begin{abstract}
Parasitic diseases have a serious impact on the world in terms of health and economics and are responsible for worldwide mortality and morbidity. The present review features the hybrid targeting involving three main enzymes for the treatment of different parasitic diseases. The enzymes Dihydrofolate reductase, thymidylate synthase, and Serine hydroxy methyltransferase play an essential role in the folate pathway. The present review focuses on these enzymes, which can be targeted against several diseases. It shed light on the past, present, and future of these targets, and it can be assessed that these targets can play a significant role against several infectious diseases. For combating viral and protozoal infectious diseases, these targets in combination should be addressed.
\end{abstract}

Keywords Infectious diseases $\cdot$ DHFR $\cdot$ TS $\cdot$ And SHMT

\section{Introduction}

Dihydrofolate reductase (DHFR) and thymidylate synthase (TS) are the enzymes involved in the folate cycle and have gained a lot of attention as the prime targets for malaria and leishmania. Serine hydroxy methyltransferase (SHMT), which is also involved in the folate cycle, is now considered an important target for leishmania, bacterial, and protozoal diseases [1]. DHFR and TS are also prominent drug targets against different diseases such as various parasitic infections and cancer. However, the lack of effective treatment owing to the toxicity and resistance are the main hurdles and have prompted researchers to find new drugs against parasitic diseases [2]. DHFR and TS are bifunctional enzymes existing as a single unit in prokaryotes, whereas in mammals, the two proteins are distinct monofunctional enzymes [3]. Dihydrofolates are converted into folate derivatives by three enzymes: DHFR, SHMT, and TS [4]. SHMT plays an

Agha Zeeshan Mirza

dr.zeeshan80@gmail.com

1 Faculty of Pharmacy, Jinnah University for Women, Karachi, Pakistan

2 College of Medicine, Umm Al-Qura University, Makkah, Saudi Arabia

3 Department of Chemistry, University of Karachi, Karachi, Pakistan essential role in the synthesis of the pyrimidine pathway in malarial parasites. Pterin and folates are required by Auxotrophic Trypanosomatids for their growth and depend on the pathway for the conversion into the reduced cofactors by pteridine reductase and dihydrofolate reductase-thymidylate synthase, respectively [5].

It was observed that among three known inhibitors of human TS ( $h \mathrm{TS})$, pemetrexed (PMX), raltitrexed (RTX) and nolatrexed (NTX) (Tables 1 and 2), NTX was found potent for Trypanosoma brucei $(t b)$ TS while the other two were found potent for $t b \mathrm{DHFR}$, hence indicating that $t b \mathrm{TS}$ can be assessed in the future for highly potent compounds [6]. SHMT expression has been correlated in tumor growth and prognosis, while it is also being targeted against malaria and has attracted a lot of attention as a drug target [7]. The two types of SHMT isoforms, cytosolic (SHMT1) and mitochondrial (SHMT2) are reported to be a potential target against cancer as they are involved in purine and pyrimidine biosynthesis and therefore play a critical role in the metabolism of cancer cells. The two isoforms have different cellular environments and play a separate role in folate metabolism. For SHMT2, the tetrahydrofolae inhibition is maintained even at alkaline $\mathrm{pH}$ while for SHMT1 it is absent. [8]. SHMT1 isoform (cytoplasmic) overexpression has been in lung cancer, and its lesser activity in lung cancer cell lines was followed by cell arrest and apoptosis [9]. 
Table 1 Drugs targeting DHFR (status and structure of drugs targeting DHFR)

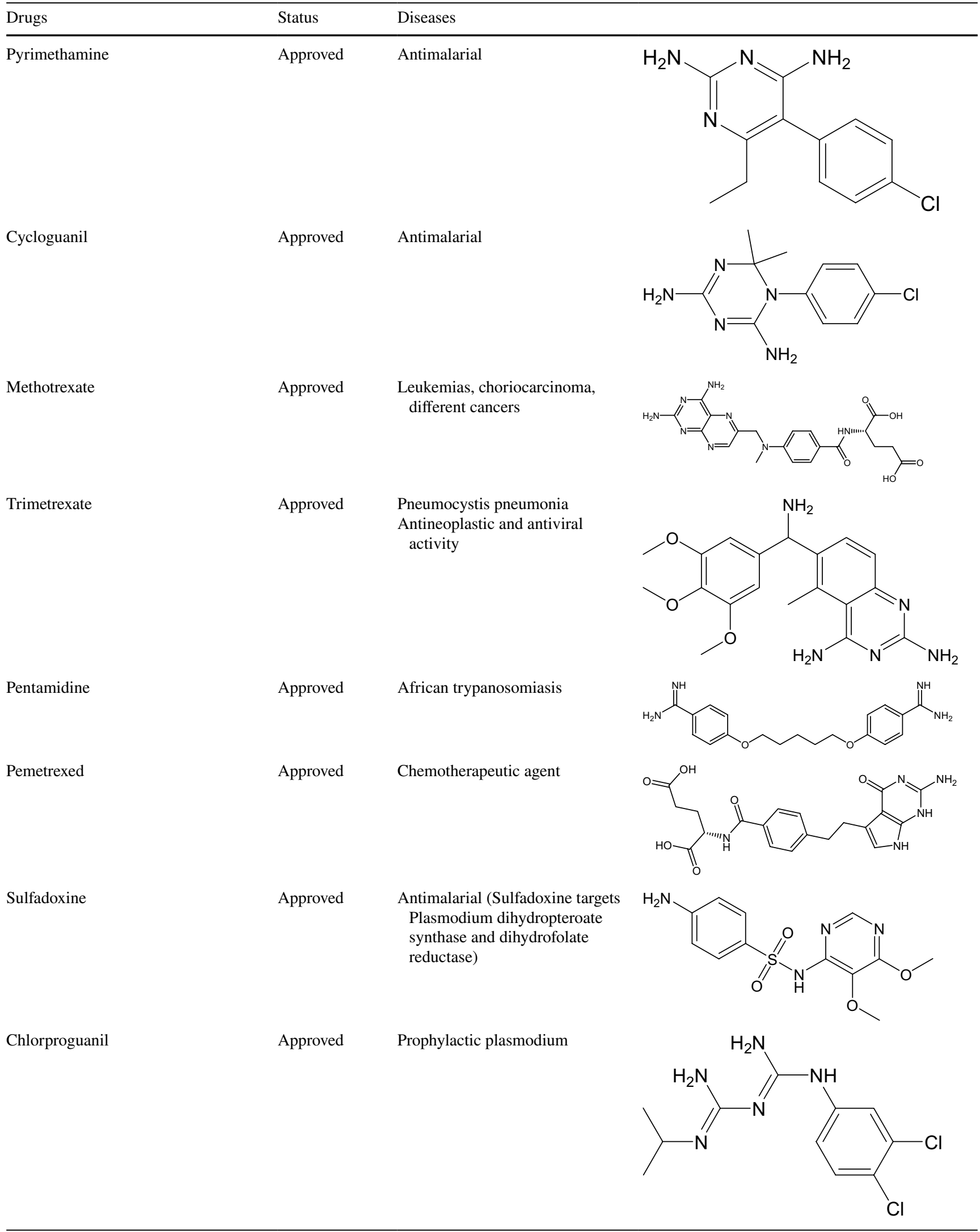


Table 1 (continued)

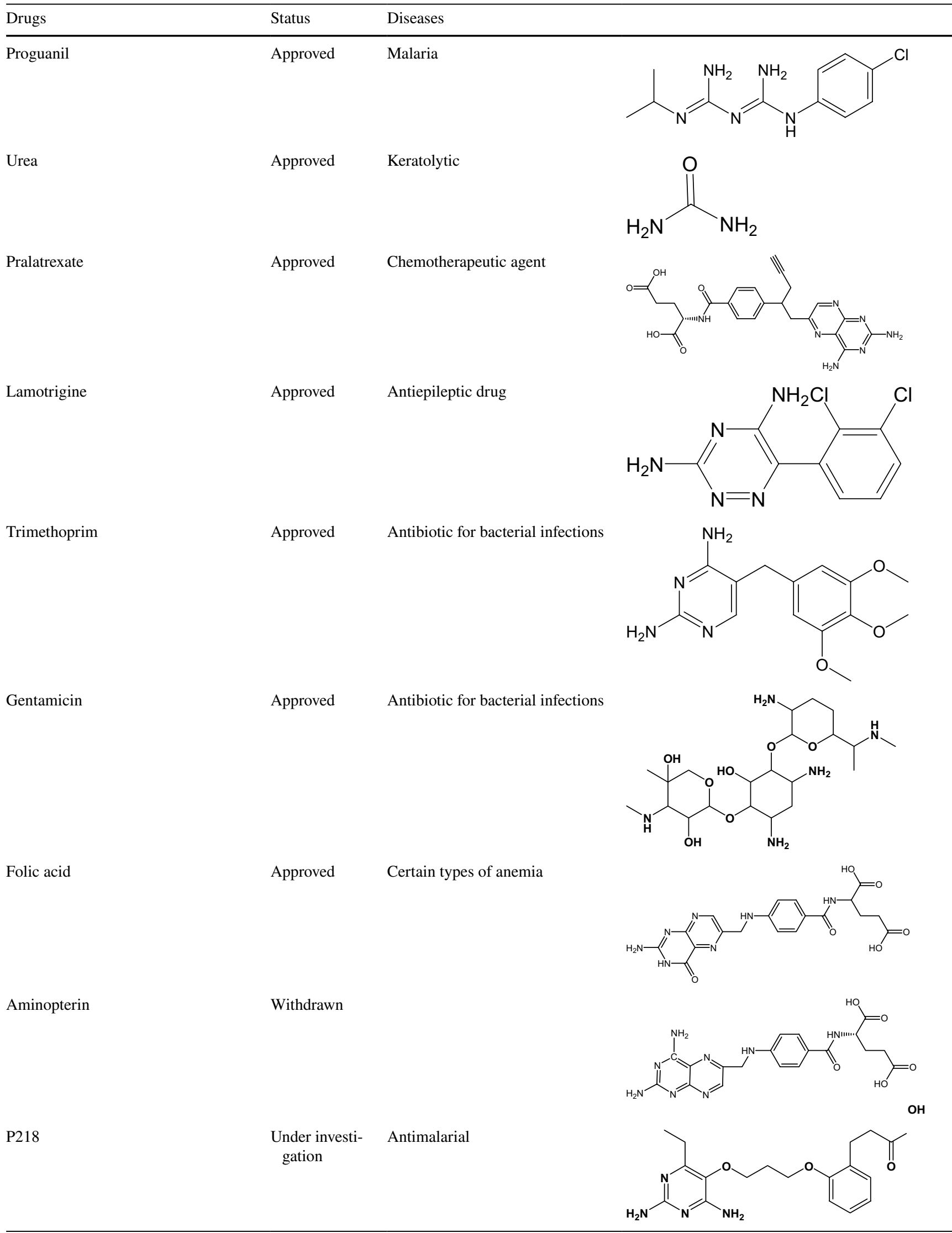


Table 1 (continued)

\begin{tabular}{lll}
\hline Drugs & Status & Diseases \\
\hline Brodimoprim-4,6-Dicarboxylate & $\begin{array}{c}\text { Under investi- } \\
\text { gation }\end{array}$ & Investigational \\
& & \\
& & \\
& & \\
2,4-Diamino-5-(3,4,5-Trimethoxy- & $\begin{array}{c}\text { Under investi- } \\
\text { gation }\end{array}$ & Investigational \\
Benzyl)-Pyrimidin-1-Ium & &
\end{tabular}

7-[2-Methoxy-1-(methoxymethyl) ethyl]-7 h-pyrrolo[3,2-f] quinazoline-1,3-diamine

7-(1-Ethyl-Propyl)-7 h-Pyrrolo-[3,2-F Quinazoline-1,3-Diamine

5-Phenylsulfanyl-2,4-Quinazolinediamine

5-Chloryl-2,4,6-Quinazolinetriamine

5-[4-Tert-Butylphenylsulfanyl]-

2,4-Quinazolinediamine

5-[(4-Methylphenyl)Sulfanyl]-

2,4-Quinazolinediamine
Under investi- Investigational gation

Under investi- Investigational gation

Under investi- Investigational gation

Under investi- Investigational gation

Under investi- Investigational gation

Under investi- Investigational gation<smiles>COc1cc(Cc2cnc(N)nc2N)cc(OCCCC(CCC(=O)O)C(=O)O)c1Br</smiles><smiles>COc1cc(Cc2cnc(N)[nH+]c2N)cc(OC)c1OC</smiles><smiles>COCC(COC)n1ccc2c3c(N)nc(N)nc3ccc21</smiles><smiles>CCC(CC)n1ccc2c3c(N)nc(N)nc3ccc21</smiles><smiles>Nc1nc(N)c2c(Sc3ccccc3)cccc2n1</smiles><smiles></smiles><smiles>CC(C)(C)c1ccc(Sc2cccc3nc(N)nc(N)c23)cc1</smiles><smiles>Cc1ccc(Sc2cccc3nc(N)nc(N)c23)cc1</smiles> 
Table 1 (continued)

\begin{tabular}{lll}
\hline Drugs & Status & Diseases \\
\hline $\begin{array}{l}\text { 5-(4-Morpholin-4-Yl-Phenylsulfanyl)- } \\
\text { 2,4-Quinazolinediamine }\end{array}$ & $\begin{array}{c}\text { Under investi- } \\
\text { gation }\end{array}$ & Investigational \\
& & \\
& & \\
$\begin{array}{l}\text { 5-(4-Methoxyphenoxy)-2,4-Quinazo- } \\
\text { linediamine }\end{array}$ & $\begin{array}{c}\text { Under investi- } \\
\text { gation }\end{array}$ & Investigational \\
\end{tabular}

5-(4-Methoxyphenoxy)-2,4-Quinazo- Under investi- Investigational gation<smiles>Nc1nc(N)c2c(Sc3ccc(N4CCOCC4)cc3)cccc2n1</smiles><smiles>COc1ccc(Oc2cccc3nc(N)nc(N)c23)cc1</smiles>

2,4-Diamino-5-Methyl-6-[(3,4,5-Trimethoxy-N-Methylanilino)Methyl] Pyrido[2,3-D]Pyrimidine

6-(Octahydro-1 h-Indol-1-Ylmethyl) Decahydroquinazoline-2,4-Diamine

Under investi- Investigational gation<smiles>COc1cc(N(C)Cc2cnc3nc(N)nc(N)c3c2C)cc(OC)c1OC</smiles><smiles>NC1NC(N)C2CC(CN3CCC4CCCCC43)CCC2N1</smiles>

N6-(2,5-Dimethoxy-Benzyl)-N6-Me- Under investi- Investigational thyl-Pyrido[2,3-D]Pyrimidine-2,4,6- gation Triamine

2,4-Diamino-6-[N-(3',4',5'-

Under investi- Investigational Trimethoxybenzyl)-N-Methylamino] gation

Pyrido[2,3-D]Pyrimidine

Sri-9662

Under investi- Antifolate gation<smiles>COc1ccc(OC)c(CN(C)c2cnc3nc(N)nc(N)c3c2)c1</smiles><smiles>COc1cc(CN(C)c2cnc3nc(N)nc(N)c3c2)cc(OC)c1OC</smiles><smiles>COc1ccc(OC)c(/C=C\c2cnc3nc(N)nc(N)c3c2C)c1</smiles> 
Table 1 (continued)

\begin{tabular}{lll}
\hline Drugs & Status & Diseases \\
\hline Epigallocatechin gallate & $\begin{array}{c}\text { Under investi- } \\
\text { gation }\end{array}$ & Flavonoid
\end{tabular}

\section{(S)-iclaprim}

\section{Under investi- In vitro activity against Gram- gation}<smiles>O=C(O[C@H]1Cc2c(O)cc(O)cc2O[C@@H]1c1cc(O)c(O)c(O)c1)c1cc(O)c(O)c(O)c1</smiles><smiles>COc1cc(Cc2cnc(N)nc2N)c2c(c1OC)OC(C1CC1)C=C2</smiles>

5-[3-(2,5-dimethoxyphenyl)prop-1-yn- Under investi- Investigational 1-yl]-6-ethylpyrimidine-2,4-diamine gation
Under investi- Investigational gation
Under investi- Endogenous enzyme cofactors gation pyrimidine-2,4-diamine

Biopterin<smiles>CCc1nc(N)nc(N)c1C#CCc1cc(OC)ccc1OC</smiles><smiles>CC(O)C(O)c1cnc2[nH]c(N)nc(=O)c2n1</smiles>

Under investi- Investigational gation<smiles>COc1cc(-c2ccccc2)cc([C@@H](C)C#Cc2c(C)nc(N)nc2N)c1</smiles> 
Table 1 (continued)

Drugs Status Diseases

5-[(3R)-3-(5-methoxy-4'-methylbiphe- Under investi- Investigational nyl-3-yl)but-1-yn-1-yl]-6-methylpy- gation rimidine-2,4-diamine

5-[(3R)-3-(5-methoxy-3',5'-dimethylb- Under investi- Investigational

iphenyl-3-yl)but-1-yn-1-yl]-6-meth- gation ylpyrimidine-2,4-diamine

5-[(3R)-3-(5-methoxy-2',6'-dimethylbiphenyl-3-yl)but-1-yn-1-yl]-6-meth-

Under investigation

Investigational ylpyrimidine-2,4-diamine<smiles>COc1cc(-c2ccc(C)cc2)cc([C@@H](C)C#Cc2c(C)nc(N)nc2N)c1</smiles><smiles>COc1cc(-c2cc(C)cc(C)c2)cc([C@@H](C)C#Cc2c(C)nc(N)nc2N)c1</smiles><smiles>COc1cc(-c2c(C)cccc2C)cc([C@@H](C)C#Cc2c(C)nc(N)nc2N)c1</smiles> 
Table 1 (continued)

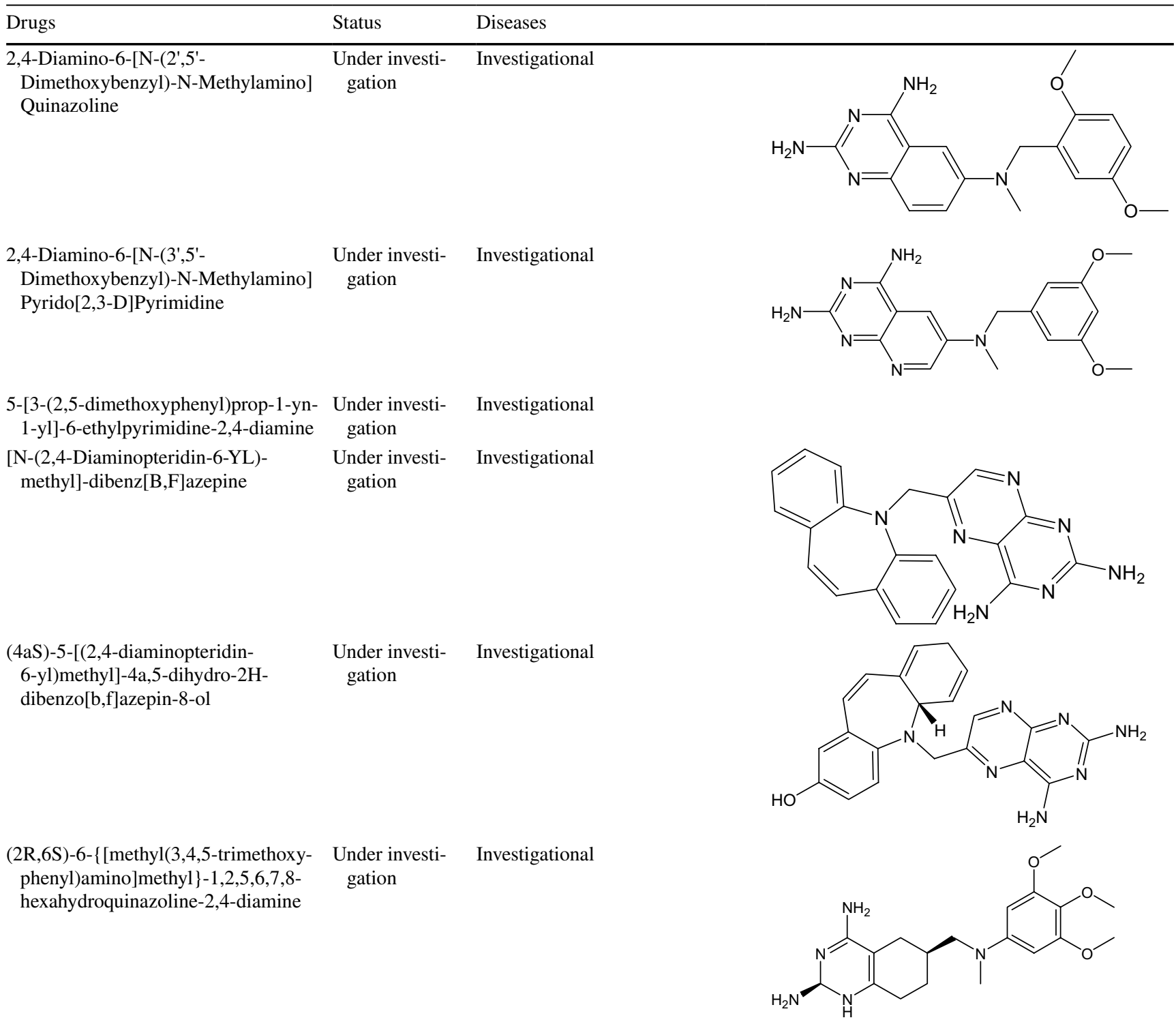

The present review focuses on the three enzymes that can be targeted against many diseases and in this regard hybrid drug designing can play a significant role in combating the targets together. The manuscript discusses the diseases in which these enzymes can be targeted. Furthermore, it describes the importance of targeting these enzymes by discussing folate pathways and also sheds light on the challenges in targeting these enzymes. The structure of the enzymes and the SAR can be used in the future for designing hybrid compounds. The current drugs and the drugs in investigational phases have also been discussed with the structures provided in Tables 1, 2, 3 .

\section{Diseases}

Malaria, an infectious disease, is caused by a parasite and has become one of the significant health issues amounting to many deaths among children, pregnant women, and others. Chemotherapy still is the most effective treatment for malaria, but parasite resistance is the primary concern of failure in the clinical treatments and therefore requires new therapeutics for its control [10]. The main objective is to search for anti-malarial therapy, to identify the new molecular targets and new compounds with known mechanisms of action [11]. The malarial parasites cannot save pyrimidine and therefore are dependent on pyrimidine biosynthesis, 
Table 2 Drugs acting targeting TS

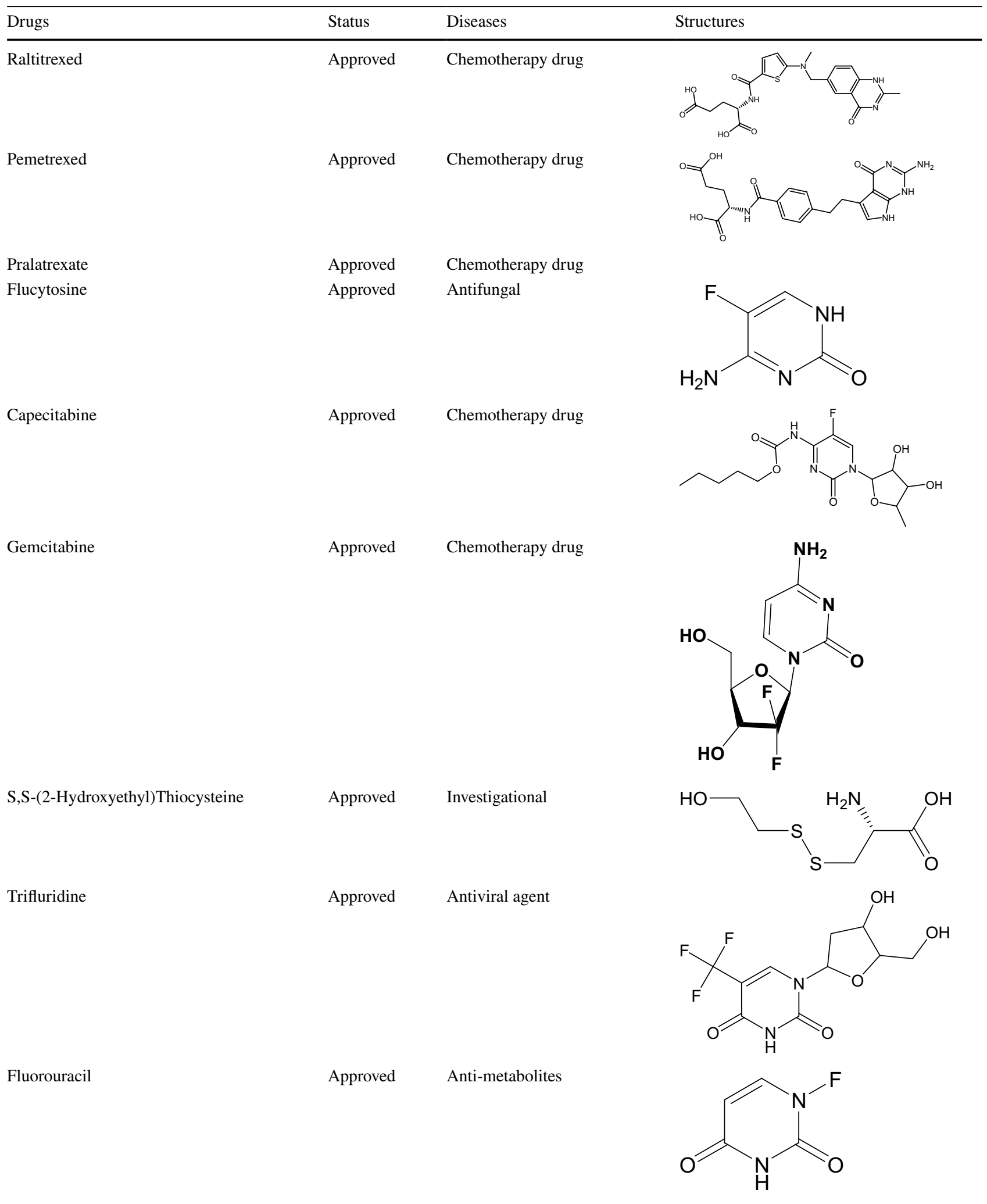


Table 2 (continued)

Drugs

ANX-510

Thymectacin

Tegafur-uracil

10-Propargyl-5,8-Dideazafolic acid

(6S)-5,6,7,8-tetrahydrofolic acid

5-Fluoro uracil

5,10-Methylene-6-Hydrofolic acid

2-(2-chloropyridin-4-yl)-4-methyl-1H-isoindole-1,3(2H)-dione
Status

Approved

Diseases

Anti-metabolites

Approved

Folate-based biomodulator drug

Approved

Colon cancer

Approved

Chemotherapy drug

Approved Investigational

Approved Investigational

E. Coli

Antineoplastic antimetabolite

Investigational<smiles>Nc1nc2c(c(=O)[nH]1)N1CN(c3ccc(C(=O)NC(CCC(=O)O)C(=O)O)cc3)CC1C=N2</smiles>

Structures
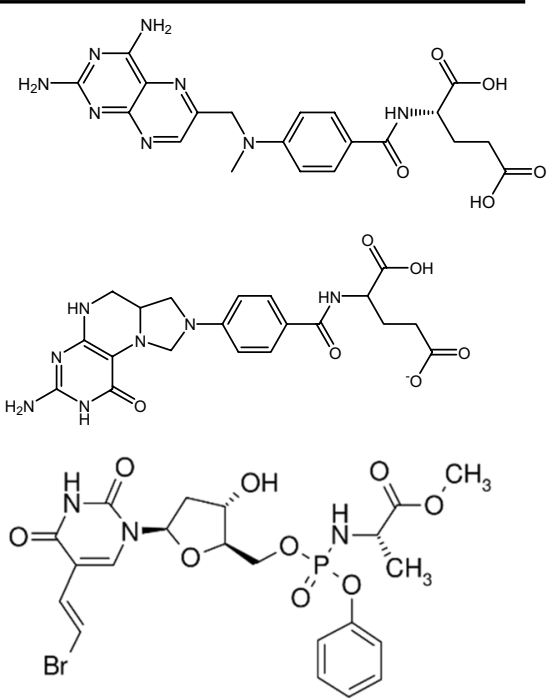<smiles>O=c1[nH]c(=O)n(C2CCCO2)cc1F</smiles><smiles>C#CCN(Cc1ccc(C(=O)NC(C)(CCC(=O)O)C(=O)O)cc1)c1ccc2[nH]c(N)nc(=O)c2c1</smiles><smiles>Nc1nc2c(c(=O)[nH]1)NC(CNc1ccc(C(=O)NC(CCC(=O)O)C(=O)O)cc1)CN2</smiles><smiles>Cc1cccc2c1C(=O)N(c1ccnc(Cl)c1)C2=O</smiles> 
Table 2 (continued)

2-(4-hydroxybiphenyl-3-yl)-4-methyl-

2-(4-hydroxybiphenyl-3-yl)-4-
1H-isoindole-1,3(2H)-dione

4-(4-methyl-1,3-dioxo-1,3-dihydro-

2H-isoindol-2-yl)benzonitrile

3-Diphenol-6-nitro-3 h-benzo[de]isochromen-1-one

Floxuridine

OSI-7904L

2,4-Diamino-5-phenyl-6-ethylpyrimidine
Status

Diseases

Structures

Investigational<smiles>Cc1cccc2c1C(=O)N(c1cc(-c3ccccc3)ccc1O)C2=O</smiles>

Investigational<smiles>Cc1cccc2c1C(=O)N(c1ccc(C#N)cc1)C2=O</smiles>

Investigational<smiles>O=C1OC(c2ccc(O)cc2)(c2ccc(O)cc2)c2ccc([N+](=O)[O-])c3cccc1c23</smiles>

Chemotherapy drug<smiles>O=c1[nH]c(=O)n([C@@H]2C[C@H](O)[C@@H](CO)O2)cc1F</smiles>

Investigational<smiles>Cc1nc2ccc3ccc(N(C)c4ccc5c(c4)CN([C@@H](CCC(=O)O)C(=O)O)C5=O)cc3c2c(=O)[nH]1</smiles>

Investigational<smiles>CCc1nc(N)nc(N)c1-c1ccccc1</smiles> 
Table 2 (continued)

Drugs
N-[2-Chloro-5-(trifluoromethyl)phenyl]
imidodicarbonimidic diamide
imidodicarbonimidic diamide

$\mathrm{N}$-(3,5-dimethoxyphenyl) imidodicarbonimidic diamide

6,6-Dimethyl-1-[3-(2,4,5-trichlorophenoxy) propoxy]-1,6-dihydro-1,3,5-triazine2,4-diamine

LY231514 tetra glu

L-methionine (S)-S-oxide

Tosyl-D-proline
Status Diseases

Investigational

Investigational

Investigational

Investigational

Investigational

Investigational

\section{Structures}<smiles>N=C(N)N(C(=N)N)c1cc(C(F)(F)F)ccc1Cl</smiles><smiles>COc1cc(OC)cc(N(C(=N)N)C(=N)N)c1</smiles><smiles>CC1(C)N=C(N)N=C(N)N1OCCCOc1cc(Cl)c(Cl)cc1Cl</smiles><smiles>CC(=O)CCC(NC(=O)CCC(NC(=O)CCC(NC(=O)CCC(NC(=O)c1ccc(CCc2c[nH]c3c2C(=O)NC(N)N3)cc1)C(=O)O)C(=O)O)C(=O)O)C(=O)O</smiles><smiles>C[S@](=O)CC[C@H](N)C(=O)O</smiles><smiles>Cc1ccc(S(=O)(=O)N2CCC[C@H]2C(=O)O)cc1</smiles> 
Table 2 (continued)

\begin{tabular}{llll}
\hline Drugs & Status & Diseases & Structures \\
\hline N-Carboxymethionine & Investigational & &
\end{tabular}

LY341770

Investigational

\section{N,O-Didansyl-L-Tyrosine}

SP-876

N-[Tosyl-D-Prolinyl]Amino-Ethanethiol

Investigational

Investigational

Investigational<smiles>Nc1nc(=O)c2c(CCc3ccc(C(=O)NC(CCc4nn[nH]n4)C(=O)O)cc3)c[nH]c2[nH]1</smiles><smiles>CN(C)c1cccc2c(S(=O)(=O)N[C@@H](Cc3ccc(OS(=O)(=O)c4cccc5c(N(C)C)cccc45)cc3)C(=O)O)cccc12</smiles><smiles>CC(=O)CC[C@H](NC(=O)c1ccc(S(=O)(=O)N2CCC[C@H]2C(=O)CCCC(=O)O)cc1)C(=O)O</smiles>

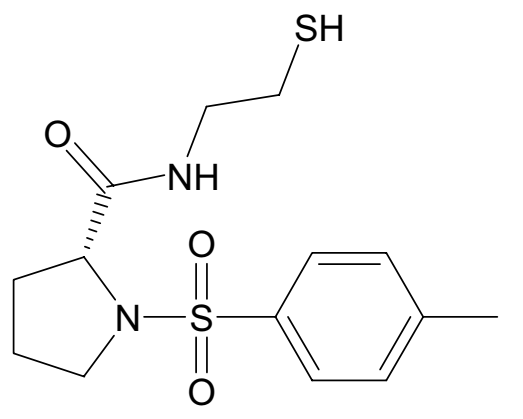


Table 2 (continued)

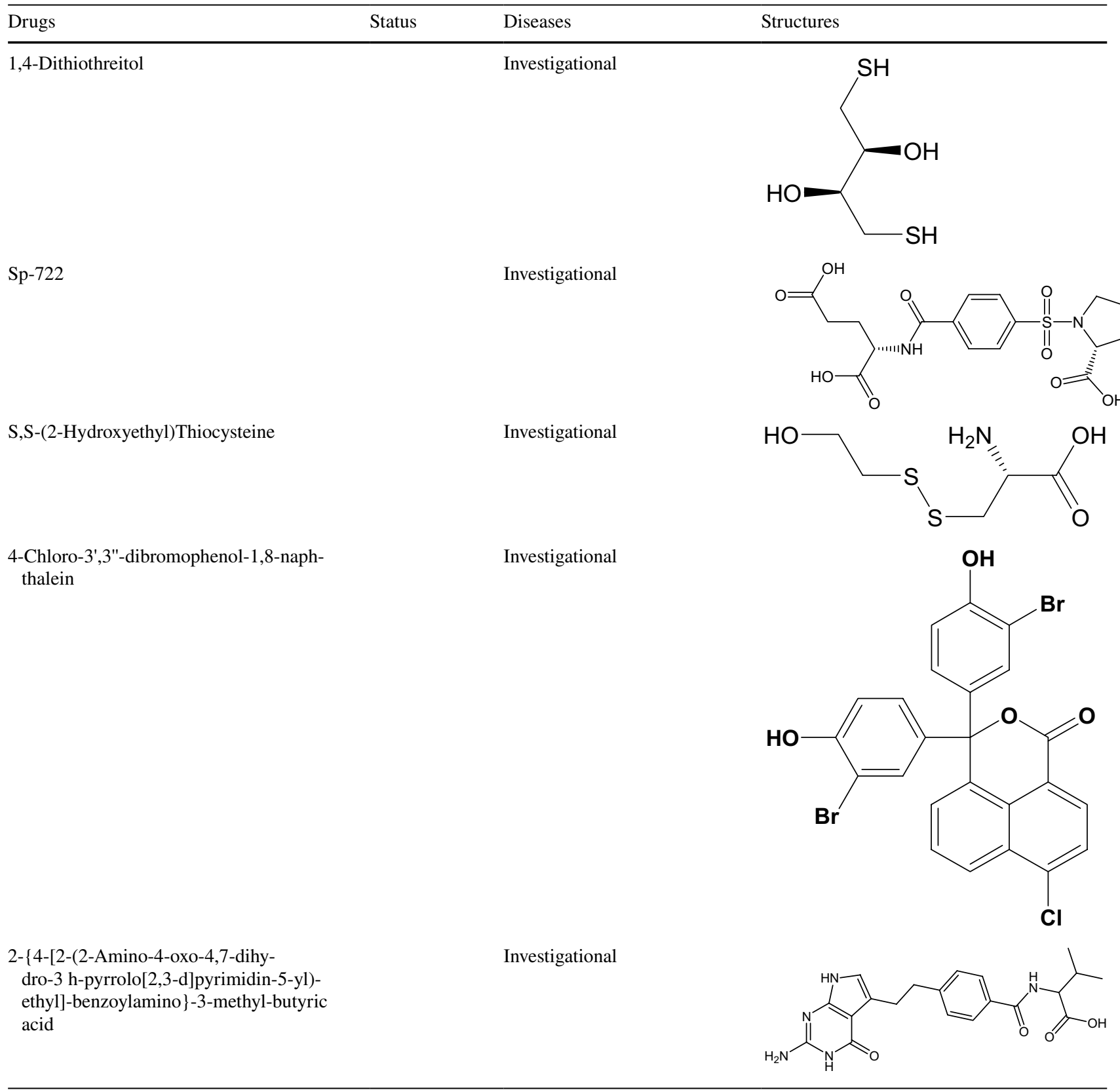

while mammalian cells can transport pyrimidine bases and nucleosides and can convert them to nucleotides. TS has gained attention as an anti-malarial target as it is involved in pyrimidine biosynthesis and is also metabolically linked to DHFR. Even TS partial inhibition may lead to cell death due to nucleotide imbalances [12]. Plasmodium SHMT has also gained importance as a new target for malaria, as it is involved in folate recycling and the dTMP synthesis cycle [13].

SHMT was an obvious candidate for the first folate biosynthetic enzymes to be quantified due to its relatively high abundance in plasmodial extracts compared to other folate biosynthetic enzymes. It is now believed that malaria can be cured by multiple target drug therapy [14-17]. The bifunctional enzyme structure of DHFR-TS also offers in designing the specific inhibitors for targeting the active sites at both domains [18].

Toxoplasma gondii ( $\mathrm{tg}$ ) is a parasite responsible for causing Toxoplasmosis, a disease involving a retina and is a congenital infection. Apart from parasitic diseases, the role of these enzymes in several viral diseases cannot be ignored. As in the case of Flaviviruses which have played a significant 
Table 3 Drugs targeted bifunctional DHFR-TS and SHMT

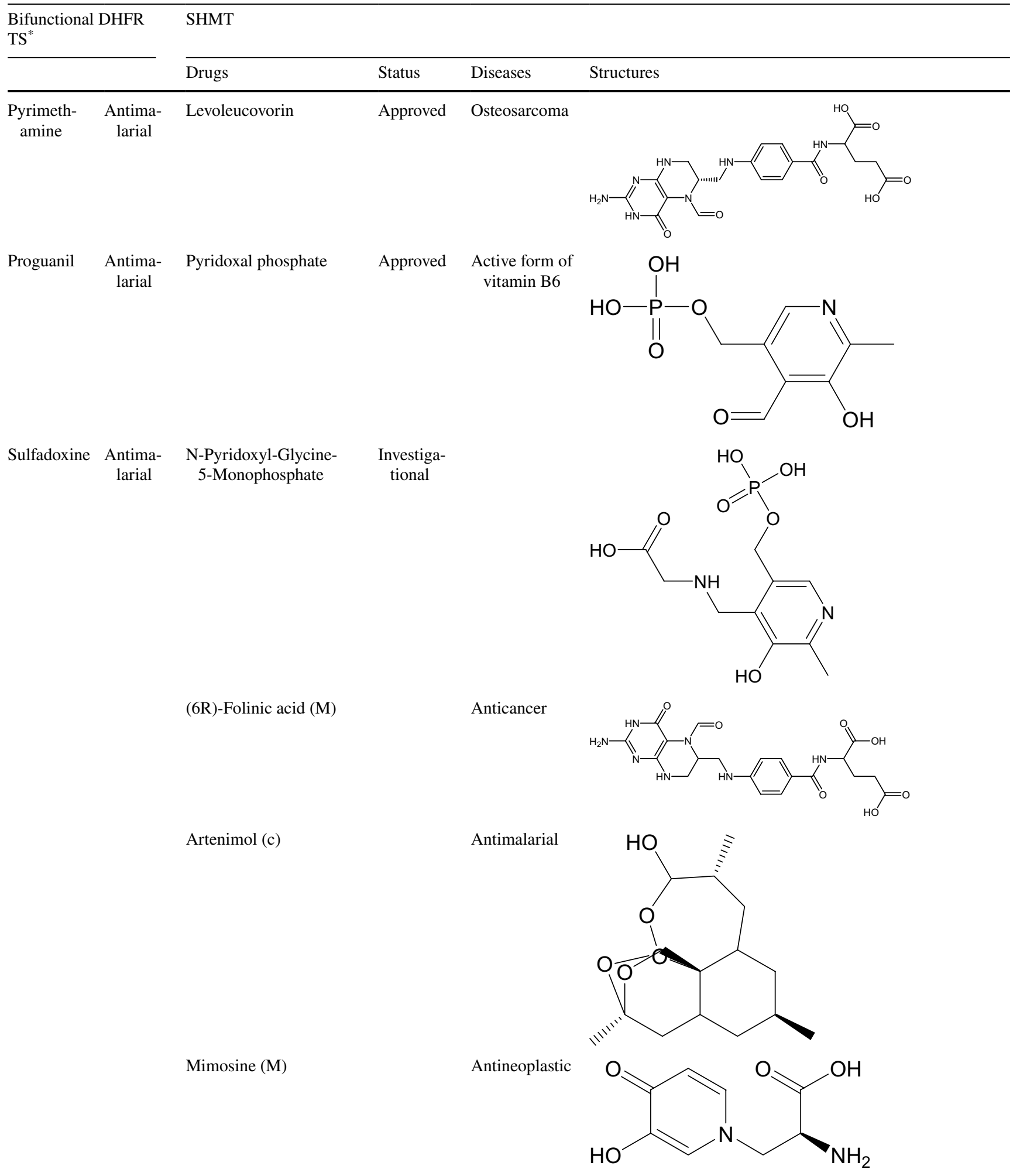


Table 3 (continued)

Bifunctional DHFR

TS*

SHMT

5-hydroxymethyl-5,6-dihydrofolic acid $^{\odot}$

Tetrahydrofolic acid ${ }^{\circledR}$

Lometrexol (M)

JPC-2056

JPC-2067-B
Diseases Structures

Investigational<smiles>Nc1nc2c(c(=O)[nH]1)N(C=O)C(CNc1ccc(C(=O)NC(CCC(=O)CC(CCC(=O)N[C@@H](CCC(=O)O)C(=O)O)C(=O)O)C(=O)O)cc1)CN2</smiles>

Investigational<smiles>Nc1nc2c(c(=O)[nH]1)N(CO)C(CNc1ccc(C(=O)N[C@@H](CCC(=O)O)C(=O)O)cc1)C=N2</smiles>

Folic acid derivative<smiles>Nc1nc2c(c(=O)[nH]1)NC(CNc1ccc(C(=O)NC(CCC(=O)O)C(=O)O)cc1)CN2</smiles>

Antifolate<smiles>Nc1nc2c(c(=O)[nH]1)CC(CCc1ccc(C(=O)N[C@@H](CCC(=O)O)C(=O)O)cc1)CN2</smiles>

Methoxypyrimidine<smiles>CC(C)NC(=N)NC(=N)NOCCCOc1ccc(OC(F)(F)F)cc1Cl</smiles>

*Structures mentioned earlier

role in the burst of infectious diseases like dengue, West Nile and Zika fevers, etc [19-22]. Zika virus infections have gained a lot of attention recently as it has caused abnormalities in the babies following maternal infections [23]. Dengue virus infection is a mosquito-borne infection and is a widespread infection. It may cause mild to severe dengue fever, even dengue shock syndrome (DSS) [24]. Viruses such as Ebola, Marburg, and filoviruses have also emerged as pathogens, which may result in outbreaks of severe hemorrhagic fever having very high mortality rates [25].

Zika virus is responsible for serious public health issues in recent years; methotrexate, a well-known DHFR inhibitor 
[26] showed an antiviral effect against the Zika virus through inhibition of DHFR. Henceforth, the DHFR pathway can be used to target the Zika virus replication, which is related to other published results against flavivirus [27]. Moreover, TS pathways have also been shown as a new therapeutic target for antiflaviviral drug development. It has been reported that flavivirus is highly susceptible to the inhibitors of thymidine synthesis and, therefore, can serve as an important target for developing antivirals [28]. Two thymidylate synthase inhibitors were effective against the Zika virus [29]. In one more study, another inhibitor of TS was found to inhibit Zika virus multiplication, which further supported that inhibitor against this target can prove to be an important antiviral drug against the Zika virus [30].

Methotrexate owing to its close structural similarity with DHFR substrate (dihydrofolic acid) has a strong binding affinity for the DHFR enzyme. It has shown a complex mode of action involving different pathways [26]. This drug has proved to be an important therapeutic agent with profound activities as an anticancer, anti-inflammatory, and immunosuppressant [31]. Methotrexate and floxuridine have been reported to slow the Dengue virus replication by targeting host DHFR and TS enzymes [27].

Influenza $\mathrm{A}$ is treated by targeting either $\mathrm{M} 2$ ion channel or viral neuraminidase by antivirals, however, the resistance of drugs for a target confer problems in the treatment of influenza A [32]. In one study, influenza A and B virus and respiratory syncytial virus (RSV) were shown to be inhibited by targeting host DHFR enzymes using cycloguanil-based analogs as 1-aryl-4,6-diamino-1,2-dihydrotriazines [33]. These compounds were found to be effective against $h$ DHFR and showed potent activities against the influenza B virus; moreover, kinetic studies revealed the competitive inhibition behavior of cycloguanil [33]. Moreover, cycloguanil derivatives were also found to be effective against $t b$ PTR 1 [34]. Henceforth cycloguanil-based analogs can prove to be a lead molecule for antiparasitic treatments, while chloroquine, amodiaquine, quinacrine, and other antimalarials were found to be effective against strains of influenza A (H1N1) virus. Hence, it was concluded that drugs that are currently available in markets could be used for targeting host cell pathways [32]. Hydrophobic interaction of iclaprim with DHFR was found to be effective against even for the resistant enzyme and was found to be equally effective against Haemophilus influenzae, and Moraxella catarrhalis [35]. From these studies, it is prevalent that more studies in this direction could make a breakthrough for these viruses.

It was observed that a phosphorylated brivudine (antiherpesvirus drug) showed binding to the TS of Varicellazoster virus (human herpesvirus), which is the cause of varicella, a highly infectious disease in humans. This binding was confirmed by solving a complex structure of the drug with the enzyme [36]. It was demonstrated that pemetrexed inhibited Kaposi's sarcoma-associated herpesvirus, reversibly inhibiting TS or DHFR proteins by interfering with DNA replication [37]. Pteridine derivatives as methotrexate, pralatrexate, and triamterene have shown diverse biological activities and can apply to several other diseases such as diabetes, osteoporosis, ischemia, or neurodegeneration. In the future, their value as therapeutics cannot be ignored while most of the derivatives are in clinical trials, and more profound research in this area is required [38].

It has also been reported that inhibitors of viral thymidine kinase if given in combination with TS inhibitors, were more effective against herpetic diseases [39].

Kaposi's sarcoma-associated herpesvirus (KSHV), also regarded as human herpesvirus is widespread cancer in untreated patients of HIV [40] and can be fatal in immunocompromised patients [37]. Numerous nucleoside analogs targeting viral polymerase have been reported for KSHV infections. Pemetrexed, as a potent anti-KSHV agent, was identified for the KSHV infection and also had anti-herpes virus activity [37].

The role of SHMT is well defined as an antibacterial and antitumor target as it supplies C-1 units for dTMP synthesis in all living organisms [41]. SHMT2 expression has been found very high in cancer cell lines and tumor tissues, and currently, anticancer drugs targeting this enzyme are under investigation [42].

\section{Folate pathway}

DHFR is a critical enzyme in the biosynthesis of the folate pathway and was primarily a target for anticancer drug discovery. Methotrexate and aminopterin belonging to the class diaminopteridines are well-known DHFR chemotherapeutic agents and are the analogues of folic acid [43], while, Lometrexol in $h \mathrm{SHMT}$ was found to inhibit both isoforms of SHMT [44].

The importance of DHFR inhibition can be assessed by the fact that it is currently used as a target in the treatment of diseases like cancer, malaria, leishmanias, and its inhibition leads to cell death by interference in nucleotide metabolism. However, its analogues with propargyl diaminopteridine were found to have antiparasitic, immunosuppressant, antibacterial activities [43]. TS is responsible for the oxidation of cofactor to dihydrofolate (DHF), and this function is unique to TS only [45]. DHFR is responsible for the reduction of dihydrofolate to tetrahydrofolate, which is further converted into the N5, N10-methylenetetrahydrofolate. This N5, N10-methylene tetrahydrofolate is further used as a reducing agent and as a source of a methyl donor by TS for the formation of 2-deoxythymidine-5-monophosphate from 2-deoxyuridine-5-monophosphate. Hence, it is apparent that the inhibition of DHFR or TS interferes with the DNA replication process and causes cell death [46]. Bifunctional 
dihydrofolate reductase-thymidylate synthase (DHFR-TS) is a validated target in African trypanosomes [47]. DHFRTS is essential for parasitic survival and can be a promising target for $t b$ [48].

It was reported that Berberine suppressed the growth of cisplatin-resistant cells by interfering with folate cycle enzymes such as DHFR and TS [49]. Berberine is a natural compound and has shown promising anticancer activities through multiple target approaches. However, further derivatization is in the process of improving its anticancer efficacy, and improvement in its pharmacokinetic profile is also in research for future anticancer compounds [50]. However, its use as an antiparasitic drug is yet to be established. Adequate levels of tetrahydrofolate (THF) are maintained by DHFR in most living creatures, as THF is involved in the biosynthesis of deoxy Thymidine monophosphate (dTMP). Deoxyuridine monophosphate (dUMP) and 5, 10-methylenetetrahydrofolate (Met-THF) are converted to dTMP and dihydrofolate (DHF), respectively by TS, while DHF is reduced to THF by DHFR. Finally, 5, 10-methylenetetrahydrofolate is regenerated by SHMT for the continuation of dTMP biosynthesis. In the cycle, one dTMP is formed after each THF molecule is oxidized to DHF, while THF is essential for synthesizing dTMP and purine nucleotides as shown in Supplementary figure (SFig. 1). Henceforth, the formation of new dTMP molecules may be stopped by inhibition of DHFR or any other enzymes in the cycle resulting in DNA synthesis interruption leading to cellular death [51]. Thymidylate (dTMP) biosynthesis impairment leads to thymine less death by decreasing levels of deoxythymidine triphosphate (dTTP) [52]. SF 1 shows the schematic pathway of the folate cycle with the role of three enzymes at different stages. In Leishmania, the Folates are reduced by the bifunctional DHFR-TS and also involve pteridine reductase (PTR1). PTR1 acts as a bypass enzyme when the activity of DHFR-TS is inhibited. Hence it is also regarded as one of the targets against trypanosomatids [53]. 4-diaminopyrimidine derivatives have been reported to possess a dual activity against PTR1 and DHFR-TS. 2,4 diaminopyrimidine derivatives, with substitution at 6 , are competitive inhibitors for both enzymes [54].

Pteridine ring, para-aminobenzoic acid, and glutamate make folic acid, which is also called pteroylglutamic acid. However, it differs from naturally occurring folates as pteridine rings are in reduced form, and they can be regarded as polyglutamated derivatives with additional single carbon units at different positions. So, the folic acid term is used as a fully oxidized compound, while folate includes folic acid and naturally occurring folates. Anti-folates have been extensively used to treat malaria, bacterial infections, various cancers, rheumatoid arthritis, and psoriasis [55]. The close resemblance of the heterocyclic rings of the antifolates in the methotrexate, pyrimethamine, and trimethoprim with the substrate make them compete with it in the recombinant DHFR-TS enzyme by producing an inhibitory effect. However, methotrexate is more potent than others due to the presence of a pteridine ring and glutamic acid [56].

\section{Challenges in targeting the enzymes}

Folate synthetic pathway in various pathogens has been successfully targeted by drugs, and these antifolates are considered safe and well-tolerated. However, in malaria, the rapid emergence of resistance has posed difficulty in the treatment by these antifolates. The resistance to the antifolates is accountable due to point mutations in the enzymes [4].

In Plasmodium.vivax $(P v)$ the mutations at three DHFR codons as 57,58 , and 117 were highly common in the antifolate resistance which was also found to be equivalent to the mutations concurring pyrimethamine resistance in P. falciparum at residues 59 and 108 [54]. In the case of TS PCR mutagenesis studies showed that mutations were more common near to the active site (Cys195) and the loop (Arg50) loop [53].

Mutations at A16V and S108T in P. falciparum DHFR induced resistance to cycloguanil while mutations at positions $51,59,108$, and 164 were related to resistance to pyrimethamine and cycloguanil [57].

Similarly in the case of $T$. Gondii in vitro mutagenesis studies showed W25R, L98S, and L134H might be responsible for drug resistance. It was also concluded that T83N mutation might concur resistance to pyrimethamine [58].

The SHMT2 structure with antifolate was resolved just recently, and few inhibitors for the SHMT have been reported, such as sulfonyl fluoride triazine derivative, leucovorin (5-formyl-THF) serine analogues, and amino acid derivatives, but none were found to be successful. Analogs of pyrazolopyran-based inhibitors were designed to target the SHMT [59]. Initially, these pyrazolopyrans based compounds were reported to be inhibitors for plant SHMT, and it was shown that further derivatization with a meta-thiophene substitution led to inhibition of plasmodium SHMT [60]. Moreover, these compounds were also found to show activity against human SHMT [9]. In another work, a pyrazolopyran scaffold-based highly potent compound was designed, however, it was observed that these compounds were not usable in vivo models owing to their rapid clearance. It was concluded that pyrazolopyrans related compounds were unstable and were found to have poor in vivo half-lives [60]. In another study, spirocyclic ligands were designed based on both 2-indolinone or dihydroindene scaffolds and a pyrazolopyran core. Few of the compounds were found to be potent against SHMT. Several compounds were found to be selective for $p f$ SHMT [61]. However, research is still ongoing to find the inhibitors for SHMT, and pyrazolopyrans 
based compounds with drug-like properties can prove to be a promising drug.

In the case of anti-malarial drug designs also, now the focus is more on the single hybrid drug designing by linking two pharmacophores together into a single agent. Therefore, the hybrid anti-malarial drug may be endorsed as the nextgeneration anti-malarial drug. However, good bioavailability, selectivity, and toxicity of the drugs, if specified will be offered several applications such as dosage compliance, minimized toxicity, and most importantly, can delay the resistance for the drug [62].

Drug resistance owing to the mutations in amino acids was the major obstacle for the treatment of diseases. Hence, DHFR-TS structural similarity from parasitic and viral strains can be used to find the conserved region and novel sites for drug targeting can be analyzed.

\section{Structure and SAR of the selected enzymes}

DHFR-TS In humans, the DHFR and TS enzymes exist as monomers, while in parasites, they exist as dimers on the TS-TS interface on the same polypeptide chain [22]. The protein-protein interface can serve as an essential target for small molecules. DHFR-TS homodimer consists of a junction region; crossover helix is present between positively charged domains of a DHFR of the adjacent monomer with a linker region that connects DHFR domains with TS. The bifunctional enzyme is believed to be involved in substrate channeling, where dihydrofolate is transferred from TS to DHFR sites. Sequence alignment between human TS and DHFR and bifunctional DHFR-TS showed that TS to be more conserved. The complex structure of the active site has shown that DHFR N-terminal is present on the TS domain shoulders. Various species of parasites have been classified into 1 and 11, based on the absence and presence of junction region in the bifunctional DHFR-TS enzyme, respectively. As in the case of LmTS (Leishmania major), the domain is present in the majority of the interface; however, for $T$. gondii $(\mathrm{Tg})$, bifunctional monomer consists of 252 residues in DHFR, 322-610 for the TS domain, and 69 for the junction region while the crossover helix makes a curve due to proline292 [63].

In one of the studies, the DHFR of the 15 protozoal species was compared with human DHFR ( $h$ DHFR), and a comparison was made. It was observed that all DHFR constitute the L-shaped cavity of the active site, with the inner portion occupied by electronegative and hydrophobic residues. This inner portion is important for catalytic function, followed by a narrower cavity with a solvent-accessible region towards the cavity's mouth. Thirty-five residues in hDHFR form the active site, and it has been reported that among humans and in protozoan DHFR, seven residues W24, T38, P66, L67, R70, G116, and T136 are conserved.

Moreover, V8, A9, F34, T56, S59, P61, and Y121 are the residues that are conserved in all DHFR with variations in only one or two species.

In another work, it was reported that binding pocket analyzed for seven inhibitors included V26, V27, A28, D48, M49, F52, T80, I84, P85, L91, I154, Y160, and T178 with the cofactor NADPH in $t c$ DHFR (Trypanosoma cruzi) and constituted hydrophobic feature [64]. It has been reported that for wild-type DHFR-TS, hydrophobicity is important for the inhibitors, while for the $\mathrm{A} 16 \mathrm{~V}+\mathrm{S} 108 \mathrm{~T}$ mutant steric factor is essential [65].

Assessing the overall charges of the residues in the active site, it was apparent that in most of the cases, it was positively charged, while CaDHFR (Crithidia Acanthocephali), LdDHFR (Leishmania donovani), and LmDHFR it was overall neutral. It was also concluded that the substrate-binding site is highly hydrophobic in most of the DHFR enzymes, while for BgDHFR (Babesia gibsoni) and $h$ DHFR it was found to be neutral [66].

Analogues of cycloguanil were shown to inhibit $P f \mathrm{D}$ HFR ( $P$. falciparum) of the wild type or mutants due to antifolate resistance. It has been reported that cycloguanil and pyrimethamine-based inhibitors against the mutant PfDHFRs S108N can be obtained if the steric clash can be avoided. The di-aminodihydrotriazine core of inhibitors was found to make core interaction with active site residue D54 of the enzyme. The most common interaction with inhibitors was observed with sulfur-aromatic M55 with the aromatic ring and halogen-aromatic with the phenyl ring of F116 [67].

It has been observed that the pyrimethamine affinity for $T g$ DHFR ( $T$. gondii) was found to be slightly greater than $h$ DHFR, and selectivity was the main issue for $T g$ DHFR inhibitors. DHFR is a validated target against toxoplasmosis, chemical optimization of marketed lipophilic drugs loaded to JPC-2056, which is in clinical development for malaria, but also JPC-2067-B (a prodrug JPC-2056) was found to be active against the $T g$ DHFR enzyme [68]. A methoxypyrimidine based compound with enhanced potency and selectivity for $T g$ DHFR was found while it has entered in phase I clinical trial [69].

It was observed that G22 in $T g$ DHFR created a cavity containing a hydrophobic residue L23 that could accommodate a small molecule, while G22 is replaced by a D21 in hDHFR. Moreover, in $\mathrm{Tg}$ DHFR, side chains of F32 and F91 near the substrate cavity can make $\pi-\pi$ stacking interactions with inhibitors [70].

In $t g$, peptide conjugated phosphorodiamidate morpholino oligomers when conjugated to arginine octamers created peptide-conjugated PMOs (PPMOs) that were found to knockdown $T g$ DHFR [71]. 
Three crystal structures of DHFR-TS from different protozoans, tc (PDBID: 3INV), $t g$ (PDBID: 4ECK), and $p f$ $(1 \mathrm{~J} 3 \mathrm{~J})$, were super imposed using the matchmaker tool of Chimera [73] and visualized using Discovery Studio.

Three DHFR-TS proteins, 3INV.pdb $(t c)$, 4ECK.pdb ( $T$. gondii), 1J3J.pdb (P. falciparum) from protein data bank [72] were overlapped using the matchmaker tool of Chimera [73] and visualized using Discovery studio [74]. From Fig. 1 of selected pdbs, it is apparent that TS is mostly conserved, and the junction region in each enzyme was different. Similarly, DHFR was not found to be having similar sequences of amino acids in observed pdbs. Moreover, the junction region of P. falciparum (Fig. 1) was found to be larger than the other two parasitic regions, as discussed earlier. Hence, designing inhibitors that may interact with DHFR or TS at the same time or junction region may have a positive outcome.

The interaction profile of DHFR-TS from several species with different ligands was assessed: C. hominis DHFRTS with methotrexate (PDBID: 4Q0D) (Fig. 2a, b), while Fig. 2c, d tc with C-448 antifolate (3INV.pdb), Fig. 2e, fTg with folic acid (4eck.pdb), and Fig. 2g, h P. falciparum with pyrimethamine $1 \mathrm{~J} 3 \mathrm{~J}$.pdb depicts the binding interaction of the DHFR active site. Figures $2 a, b$ and $e, f$ showed that the Pteridine motif was involved in pi-pi stacking and hydrogen bonding with mostly Valine, Alanine, Phenylalanine, Threonine, and Asparagine. While Arginine was found to make a charge and van der Waals interaction with the carboxyl group of the compounds. Figures $2 \mathrm{c}, \mathrm{d}$ and $\mathrm{g}$, $\mathrm{h}$ indicated the triazine group to interact in the form of hydrogen bonding and pi-pi stacking with Aspartate, Phenylalanine, Isoleucine, and Alanine while chloro benzene was found to pi-pi bond with Phenylalanine and Isoleucine.

The DHFR active site is just opposite to the orthogonal active site of the TS in the same monomer, while the distance of the active site TS to that of the DHFR active site on the adjacent monomer on the same face is $\sim 75 \AA$. ChDHFR-TS (C. hominis) and PfDHFR-TS showed a similar orientation of the active sites. However, for LmDHFR-TS, TS constitutes the majority of the interface region through $\beta$-sheet from each monomer, and active sites are present on the same side of the monomer. LmDHFR-TS has a very short junction of 2 amino acids. The conserved residues involved in the binding of the ligand and substrates were

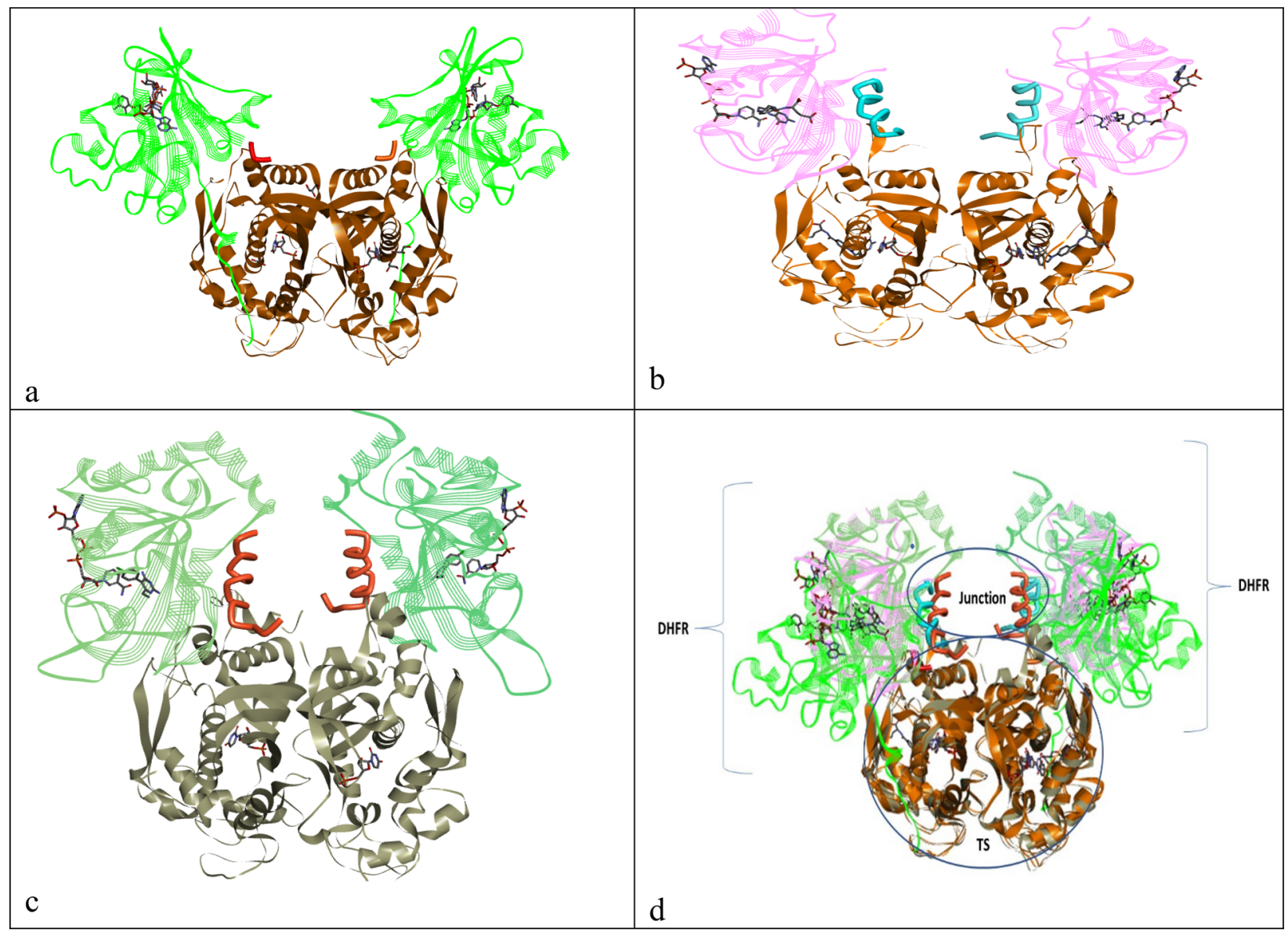

Fig. 1 TS-DHFR structures of a T. cruzi, b T. gondii, $\mathbf{c}$ P. falciparum, d overlapped structures of all three parasites 


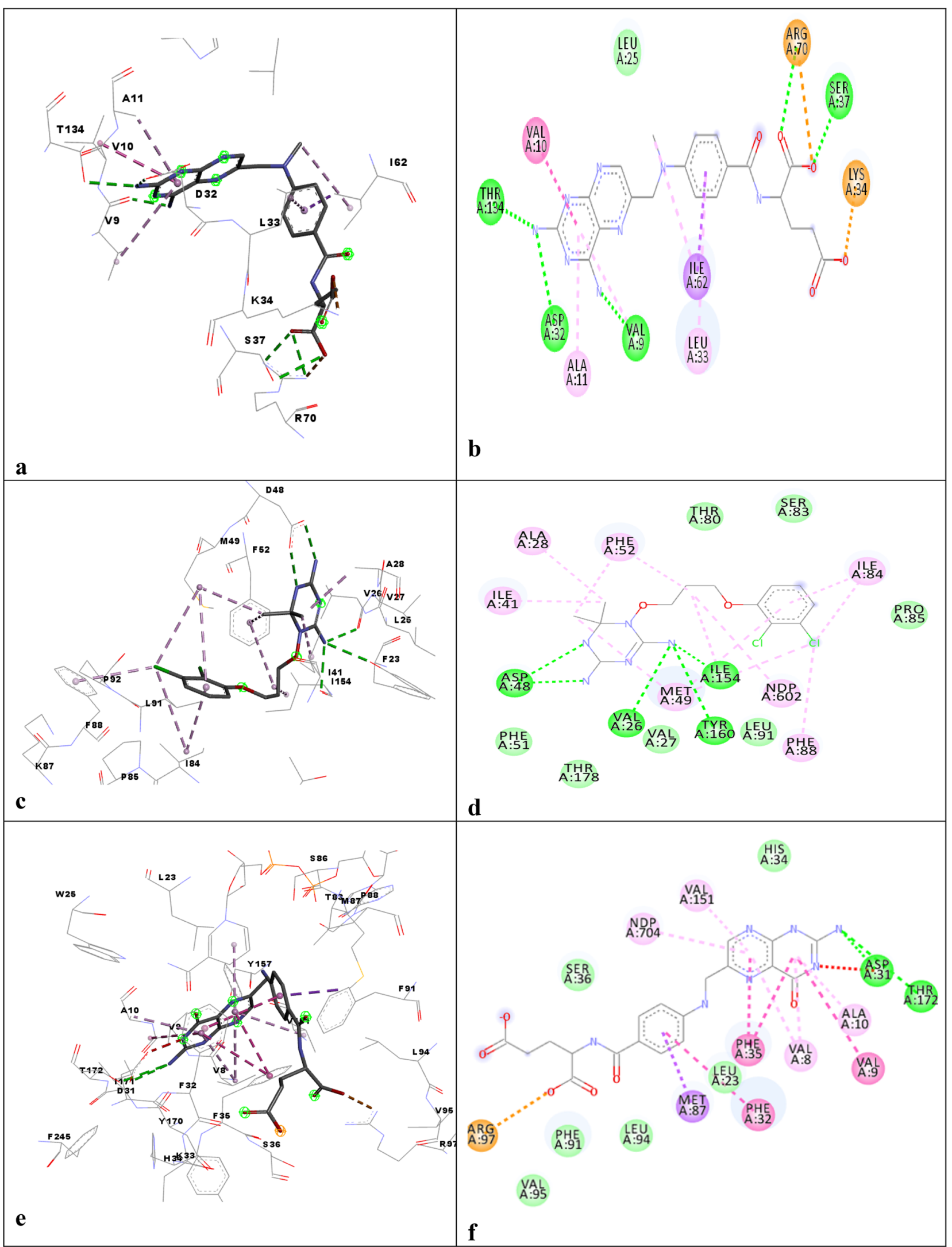

Fig. 2 DHFR domain 3D and 2D interaction profile of the a, b 4Q0D.pdb, c-d 3INV.pdb, e, f 4eck.pdb, g, h 1j3j.pdb 


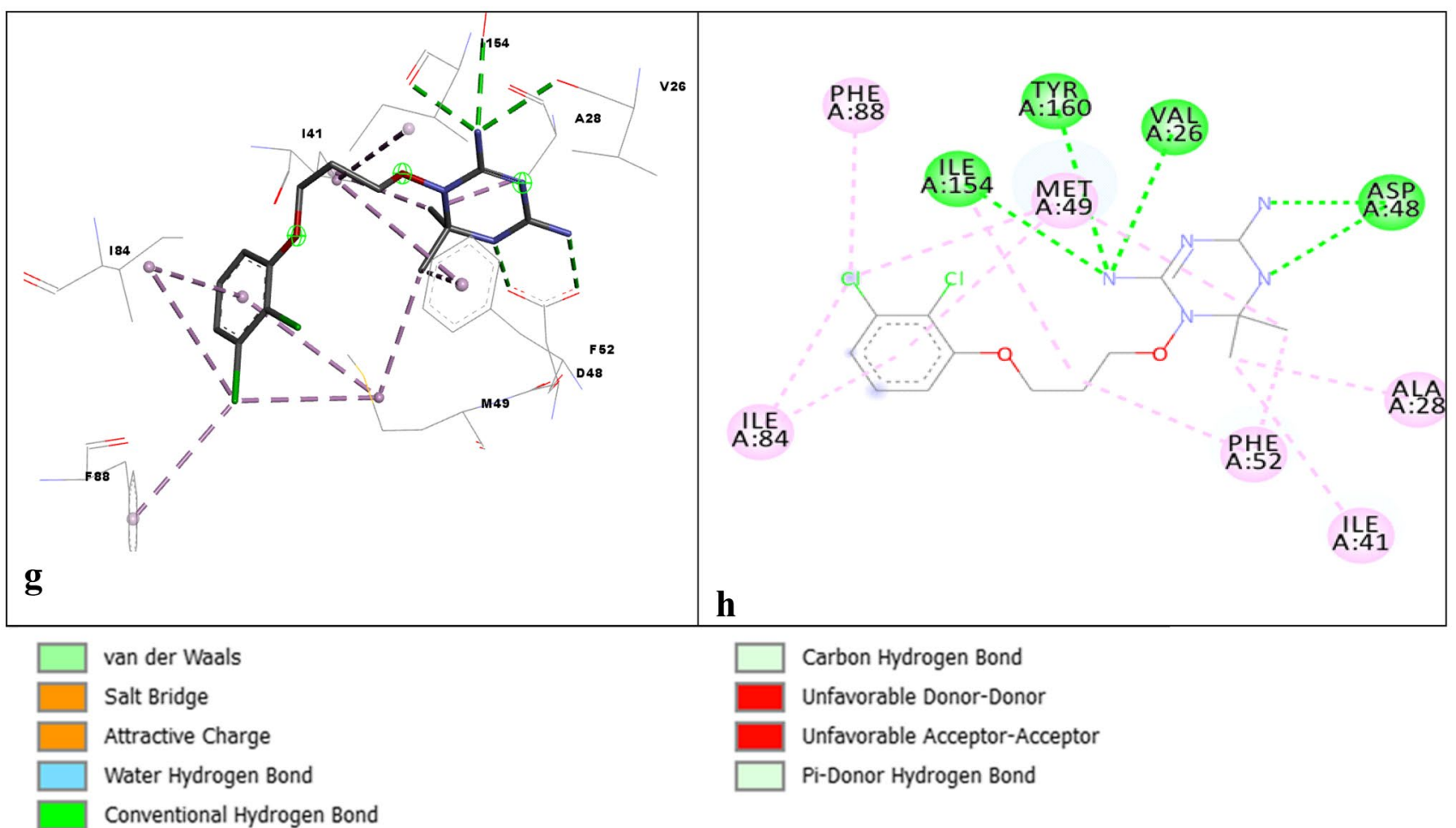

Fig. 2 (continued)

R344, R510, R469, and R470 from the adjacent monomer, and I402, D513, L516, F520, and M608 [63]. Figure 3a, b shows the binding interaction profile of the Cryptosporidium hominis with 2-amino-4-oxo-4,7-dihydro-pyrrolo[2,3d]pyrimidine-methyl-phenyl-L-glutamic acid (4Q0D.pdb), Fig. 3c, d tc with UMP (3INV.pdb) and Fig. 3e, f Tg with 10-Propargyl-5,8-dideazafolic acid (4eck.pdb). Figures 3a, b and e, f Tryptophan, Methionine was found to interact with pyrimidine and nitrogen rings. Isoleucine, while Fig. 3c, d Aspargine and Valine with triazine amine group Isoleucine and phenylalanine with Chloro amine group.

In the case of $L$. major, electrostatic channeling is supposed to be responsible for transferring the dihydrofolate to the active site of DHFR from the active site of TS so it can be converted into tetrahydrofolate. The shallow grooves with mostly basic residue were found to connect the two enzyme active sites. It has been suggested that targeting this shallow groove can prove to be significant for specific therapies against protozoal diseases [75].

There is the presence of additional interdomain contacts in PfDHFR-TS owing to its large junction region and two additional sequences (insert region) in the DHFR domain from residues 20-36 and residues 64-98. However, the ChDHFR-TS one insert region is present. It has been suggested that for DHFR and TS functions, the role of $\mathrm{N}$ is important; based on protozoal DHFR-TS structures and sequences, it has been classified into two structural families.
One case is characterized by a long junction region, a part of which is used for attachment of DHFR-DHFR and DHFR-TS interdomain as in PfDHFR-TS and ChDHFR-TS. The second case is characterized by a short junction and the presence of a long N-terminal extension for the contact of DHFR-TS interaction [76].

It has been observed by the $C h$ DHFR-TS crystal structure that one DHFR domain of the dimer is linked to the other DHFR domain by the crossover helix making hydrophobic interactions. It moves back to the original monomer to complete the DHFR and TS domains [22]. From E. coli DHFRfolate-NADP ${ }^{+}$ternary complex, it was observed that the M20 loop adopts different confirmation as open-close or occluded according to the catalytic cycle, which is also the most flexible region of the DHFR [77].

\section{SHMT}

SHMT, a pyridoxal 5' phosphate-dependent enzyme, is responsible for the formation of glycine from serine [78], and its activity has been observed in different parasites such as Trypanosoma cruzi (tc), Trypanosoma rangeli, Leishmania spp., and Crithidia fasciculata [79]. The crystal structures of SHMT from prokaryotes, protozoans, and eukaryotes have been found to show a similar characteristic fold as other types I pyridoxal phosphate (PLP) enzymes [78]. 


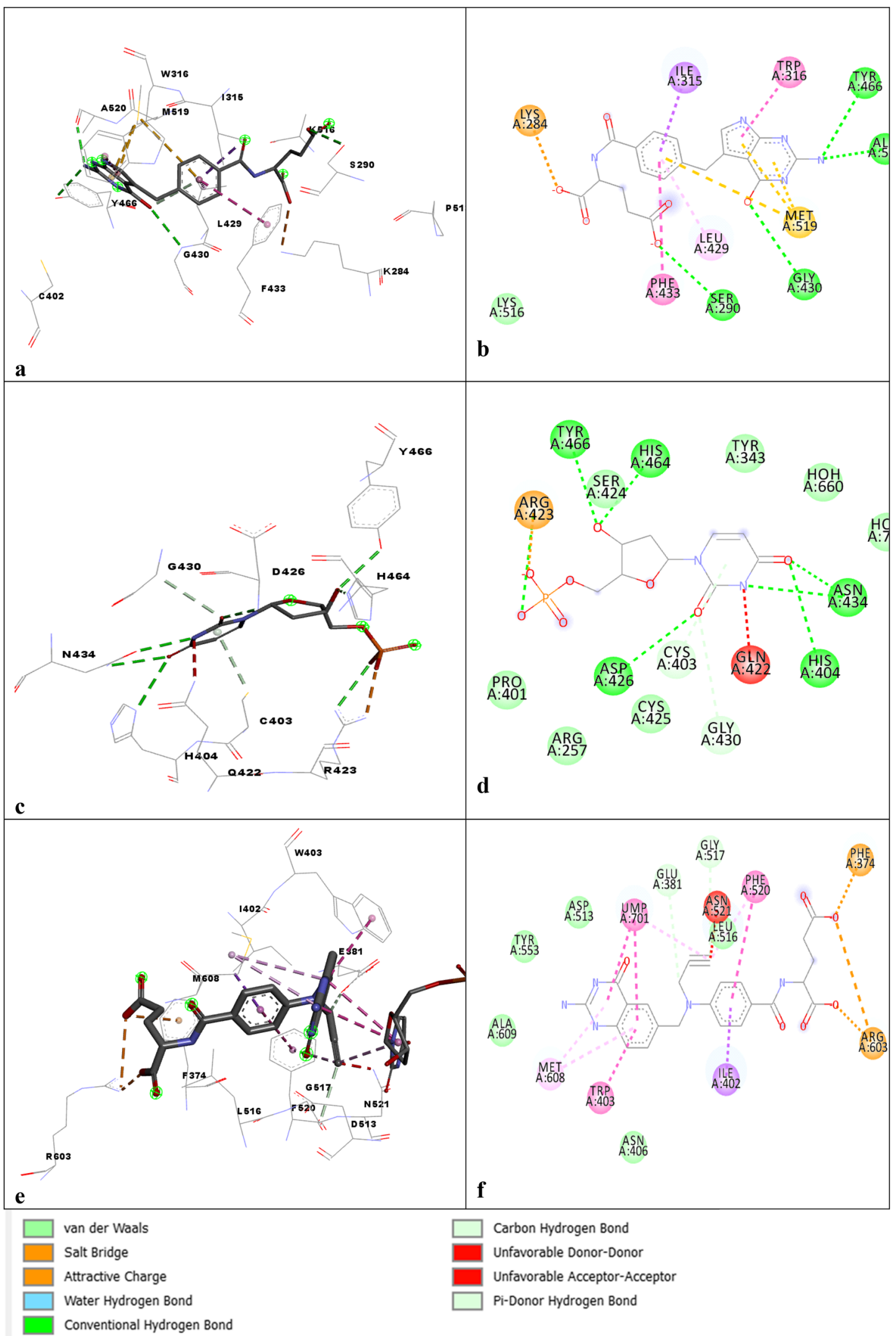

Fig. 3 TS Domain 3D and 2D interaction profile of the a, b 4Q0D.pdb, c, d 3INV.pdb, e, f:4eck.pdb 
Mostly all prokaryotic SHMTs are homodimers, while eukaryotic consist of homotetramers, it is regarded as highly conserved protein. It has different isoforms, and in most eukaryotes, it exists in cytosolic and mitochondrial isoforms [80].

Plasmodium falciparum $(p f)$ and Leishmania have two isoforms of SHMT, one localized primarily to the cytosol and the other to the mitochondrion. tc Coccidians, tg, and Neospora caninum have one isoform of SHMT mainly to be existing in the cytoskeleton [79]. However, in trypanosome $C$. fasciculata it exists in three isoforms i.e., mitochondrion, cytosol, and glycosome.

It has been reported from 55 SHMT sequences and structures of the enzymes that K71, Y72, R80, D89, W110, S202, C203, H304, H306, and H356 residues are essential for upholding the oligomeric structure, whereas D227 and K256 were found to be involved in maintaining the tetrameric structure and catalysis [81].

In humans, two isoforms are present, having shares $66 \%$ amino acid sequence resemblance with similar catalytic characteristics. SHMT2 in mitochondria is responsible for the synthesis of glycine and formate, while cytosolic SHMT1 is played a role in the biosynthesis of deoxythymidylate (dTMP) [82].

The binding profile of lometrexol, methotrexate, and raltitrexed in $h \mathrm{SHMT}$ was found to be similar to those of leucovorin and the chemical structures of all these drugs are shown in Tables 1, 2 and 3 [83]. Leucovorin was found to show inhibition at low micromolar levels for both isoforms but could not be used clinically due to its conversion in other folic acid derivatives [44].

It has been reported that $h$ SHMT 2 undergoes a transition from a dimer to a tetramer after PLP binding. Lometrexol in $h$ SHMT was found to be a more potent inhibitor for both isoforms. It was also observed that the binding site residues of the two isoforms were entirely conserved, with the only difference with the two residues Y176 and F317 in hSHMT2, which are F153 in $h$ SHMT1. Moreover, the PLP cofactor was formed internal aldimine with K280 in $h$ SHMT2-PTX complex while it formed glycine-PLP external aldimine in the mSHMT1 [44].

Trichomonas vaginalis, a unicellular parasite, is responsible for trichomoniasis, one of the most common diseases which are sexually transmitted. Trichomonas vaginalis SHMT consists of K251 as an active site residue that forms internal aldimine with PLP and exists as a dimer. For $h$ SHMT presence of His 158 is vital to create a dimer interface with other H158. Thereby forming a symmetric tetrameric quaternary structure [80].

Plasmodium spp. consists of two SHMT isoforms, SHMT1, which is functional, and an SHMT2 (putative allele). These isoforms are not similar and share only $20 \%$ similarity. It is believed that SHMT1 is important for the survival of the malarial parasite. It has also been reported that the initial $\mathrm{N}$ terminal region of $P$ fmSHMT is important for targeting [84]. It has been hypothesized that $P v$ SHMT exists as a dimeric protein and is similar to PfSHMT1, and there is a difference between the PvSHMT1 and hSHMT1. Hence a selective drug can be designed for the inhibition of plasmodium SHMT [85]. As the most abundant folate pathway protein in PfSHMT was the first protein to be searched for its inhibition has shown to be lethal to the parasite. A few of its structural characteristics are also different from other reported SHMTs. The two distinct cysteine pairs viz C125 and C364 are absent in $h$ SHMT, and in parasites, they serve as a redox switch for regulating the THF-dependent catalytic function of the enzyme.

Moreover, a ligand binding environment is different in malarial and human SHMT; hence it can assist in designing parasite specific-inhibitor [86]. It has been reported that SHMT can be an effective target for vector mosquito population control [87] while malarial SHMT can be a suitable target for parasite malaria [7]. Plasmodium-DHFR mutations at residues 51, 59, 108, and 164 have concurred resistance to antifolate drugs [88]. In plasmodium SHMT, there is a presence of two loops and a cysteine pair which is absent in human SHMT. Analysis has shown that these two residues act as a switch for the regulation of THF-dependent catalytic function. Henceforth it has been suggested that this enzyme inhibitor could be selective against a parasitic enzyme [86]. Among two isoforms of SHMT in Plasmodium spp. SHMT1 has been indicated as a valid target anti-malarial drug [84].

$P v$ SHMT (Plasmodium vivax) exists as a homodimer with two active sites in each monomer, and both active sites can be targeted for the ligands [59]. In human SHMT1, a flap motif is present, which connects the $\beta$ strand and $\alpha$-helix. However, this motif is not present in PvSHMT. It is hypothesized that this motif might have a role in THF binding to the substrate and inhibition. In the case of $P v$ SHMT, the THF binding pocket consists of catalytic dyad C125 and C364, which act as a redox switch [89]. However, designing a selective inhibitor against parasitic SHMT will be challenging, while the outcome may be beneficial owing to the conserved nature of the protein.

Two pdbs were selected from the protein data bank [72], as 4O6Z.PDB ( $P$. falciparum), 4TMR.PDB ( $P$. Vivax), and visualized in Discovery studio [74] as shown in Fig. 4a. The THF molecule consists of a pterin moiety, para-aminobenzoic acid ( $p \mathrm{ABA}$ ), and a glutamate tail, as shown in Fig. 4b. Similarly, there are two sub-pockets; one is a pterin binding pocket with a small lipophilic pocket within it, while the second one is the $p$ ABA channel, which is aligned by hydrophobic residues as shown in Fig. 4c, d [61].

Each monomer of PfSHMT homodimer consists of three domains, N-terminal (1-34), the $\mathrm{C}$ terminal (291-442), and the largest of all domains, the PLP/substrate-binding domain 


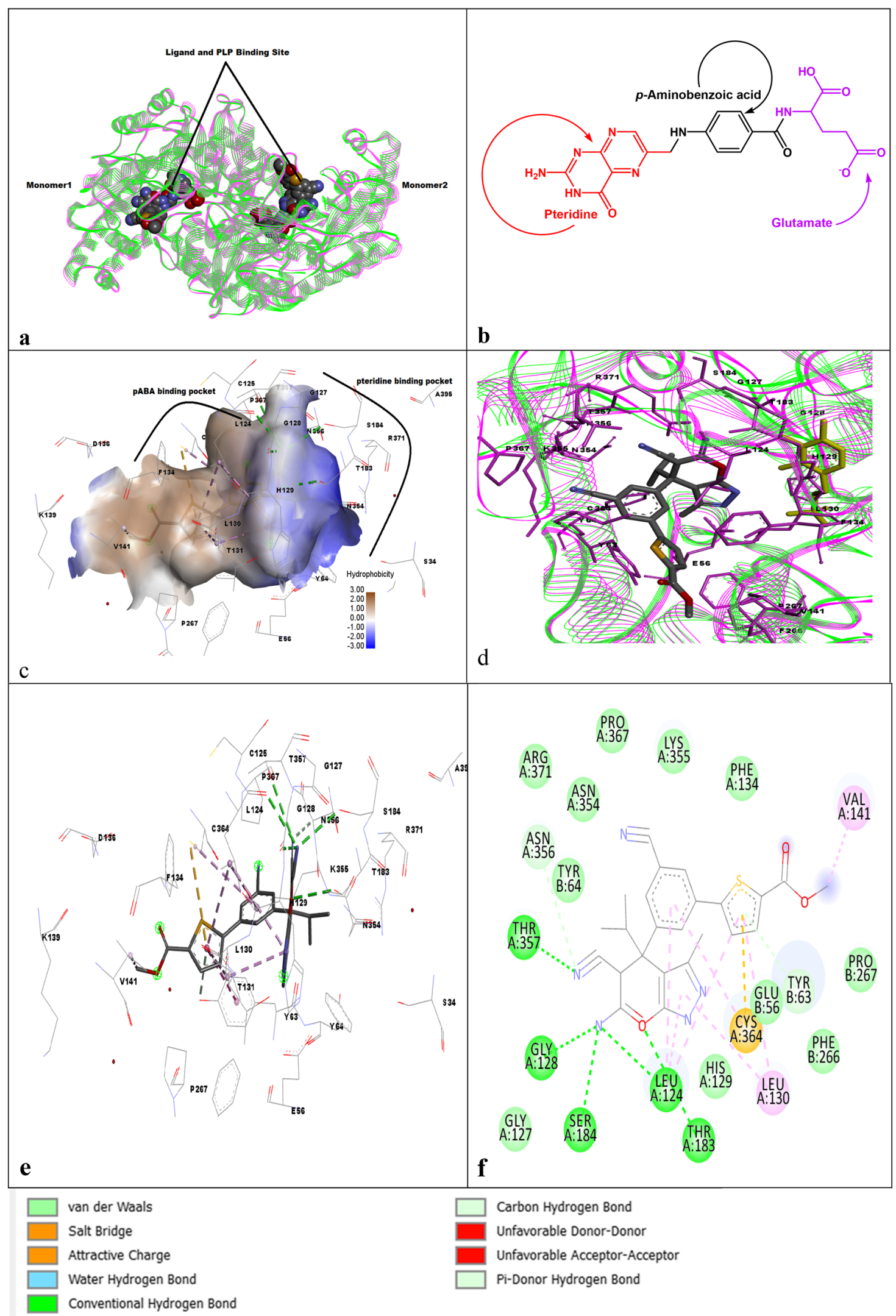

Fig. 4 a SHMT over lapped structures of 4tmr.pdb with 4o6z.pdb, b structure of folate, c, $\mathbf{d}$ structures of 4tmr.pdb and 4o6z.pdb with highlighted molecule as plp of 4o6z.pdb, e, f 3D and 2D interaction profile of the 4TMR.pdb 
(35-290). The C-terminal domain of each protomer along with the PLP binding domain makes the THF and PLP binding sites. The residues involved in substrate binding were observed by overlapping the crystal structure with EcSHMT, and it was found that S34, Y54, Y64, H129, T183, D208, H211, T234, H236, G272, and R371 are important for binding [86].

To design anti-malarial inhibitors of PfSHMT, it has been suggested to avoid using glutamate tail of 5-formyl6-hydrofolic acid (FFO), and if the tail is more extended, then both negative and positive charges should be balanced at the right positions [90].

The two proteins were overlapped, as shown in Fig. 4a; it was observed that most of the regions were conserved, as shown in Fig. 4a. The inhibitor in the 4TMR.pdb structure was used to indicate the binding residues of 406.pdb, as shown in Fig. 4c, d. PLP is also highlighted in Fig. 4d to show its binding site in the two proteins. The pyrazolopyran core binds in the pteridine pocket, making several $\mathrm{H}$-bonds to the protein, while the biaryl motif is present in the extended channel and the $p \mathrm{ABA}$ side chain of THF, as shown in Fig. 4e, f. The bicyclic pyrazolopyran (Fig. 4e, f) was found to show a similar interaction pattern as THF aminopyrimidinone moiety. T357, E56, T183, L124, and G128 were involved in the hydrogen bonding. L130 and H129 were involved in the van der Waals interactions. Y64, R371, S184 were also involved with ligand interactions, as shown in Fig. 4e, f. Figure 4e, f Oxygen of the ring makes hydrogen bonding with Leucine while Glycine, Serine, and Threonine were found to interact with Nitrogen of the ring. Cysteine was found to interact with a sulfur ring.

\section{Drug design and new molecules}

To treat complex diseases, multi-target inhibitors have presented a new vision for the pharmaceutical industry, but designing such inhibitors is a significant challenge for medicinal chemists [91].

Different heterocyclic nitrogen-containing compounds are not only part of natural compounds but are also playing an important role in modern drugs. Some of the heterocyclic nitrogen-containing compounds that have shown activities against different infectious diseases are discussed below. A quinazolinone is a building unit of alkaloids that occur naturally [92] has shown a range of activities like antimicrobial, anti-malarial, anticonvulsant, anticancer, antileishmanial, anti-inflammatory, etc. [93]. Few of the quinazolinone hybrid compounds had potent anti-malarial activity and an in silico studies were also carried out for these compounds [94]. Methoxylated 2-benzyl thioquinazoline-4(3H), which also belongs to this class, has been reported to target DHFR and possess antitumor activity [92].
A TS inhibitor of this class as raltitrexed is an antifolatebased quinazoline analog with antitumor activities [95], while OSI-7904L is a benzoquinazoline folate analog with liposomal-encapsulation of OSI-7904 [16]. OSI-7904 is a potent TS inhibitor structurally related to the folate cofactor, and its binding to TS in the complex with dUMP is not affected by 5,10-methylenetetrahydrofolate [96]. Trimetrexate also belongs to this class of compounds [97]. Trimetrexate glucuronate (non-classical antifolate) used to treat Pneumonocystis carinii pneumonia in AIDS patients shows its effect by inhibiting DHFR [98]. Trimetrexate/folinic acid, also referred to as leucovorin combination, is both effective and nontoxic in the treatment of pneumocystis carinii [99]. Several available drugs such as metolazone, methaqualone, ketanserin [16] have been approved for different health conditions. However, the most recent patents focus more on the anticancer activities of quinazoline and quinazolinone scaffold-containing molecules [100]. Theoretically, these compounds have shown excellent therapeutic values on several drug targets. It is highly possible that optimized quinazoline analogs along with SAR on the targets can play a significant role in enhancing the potency and eliminating the side effects of this class of compounds. It has been suggested that the substitution on the basic quinazoline nucleus may further enhance its activity by utilizing hybrid pharmacophore and bio-isosteric incorporation [101].

Among a series of fluorine-containing quinoline hybrids, the thiosemicarbazide analogues possess good anti-malarial activities [102]. A hybridized 4'-fluoro-amodiaquine was more effective than chloroquine for the resistant $P$. falciparum strain [103]. 4-Aminoquinolines have shown antimalarial activity due to the quinolinic ring, which modifies the parasite heme metabolism and has shown strong interaction with PfDHFR in docking studies. Different combination of artemisinin with other anti-malarials or antibiotics is now prescribed for the treatment of malaria as it is believed that the combinations act synergistically or possess a different mechanism to prevent drug resistance. Benzophenanthridine alkaloid, which is derived naturally, showed potent activity against DHFR [104]. Pyrroloquinoline alkaloids, naturally occurring alkaloids such as febrifugine and isofebrifugine were found to have excellent anti-malarial activity [100]. However, its anti-malarial efficacy is reduced in intravenous administration [105], and strong side effects have restricted them from treatment against malaria. However, their derivative with lesser side effects may help in the treatment of malaria and other infectious diseases [106].

Anti-malarials have proven to be potent agents against toxoplasmosis and the anti-malarials as quinolines, endoperoxides, pyrazolo[1,5-a]pyrimidines, and nature-derived peptide-based parasiticidal agents can serve as good therapeutics against toxoplasmosis chemotherapy [107]. 
Different hybrid compounds such as quinoline-ferrocene, quinoline-antibiotics as cinnamic acid, quinolines, and anticancer drugs, quinoline-mercaptopurine, quinoline, and sulphonamide moieties, quinoline, and other ring systems were also reported with good anti-malarial activity. Hybrid compounds containing piperazine ring were found to show a high level of cross-resistance and in silico docking studies showed strong interactions with plasmodial DHFR enzyme [108]. Hybrid drugs were prepared by incorporating endoperoxide in aminoquinoline or acridine moiety and were highly active against malaria. The trioxaquine, a hybrid compound that has 1,2,4-trioxane and an aminoquinoline as pharmacophores, are in the clinical stage and may be used via the oral route [62]. However, biochemical targets specific for trioxaquines, and the trioxolaquines could not be elucidated [109].

The pyrimidine and triazine-based analogues possess potent antileishmanial agents, along with other pharmacological activities [92]. Anti-malarial activity of $p$ ABAsubstituted 1,3,5-triazine derivatives series was tested, and two potent compounds were assessed from the series [110]. Molecular hybrids having pyrimidine and aryl/heteroaryl groups linked by 1,2,3-triazole were found to possess in vitro anti-plasmodial activity [111].

Among arylpiperazine series 5-(4-(3-(2-methoxypyrimidin-5-yl)phenyl)piperazine-1-yl)pyrimidine-2,4-diamine was found to be a good inhibitor for $t g$ DHFR and can be further tested for pre-clinical trials [20]. The new hits of thiazole-1,3,5-triazine derivatives were identified as antimalarials targeting $P f$-DHFR [112]. Lamotrigine, a phenyltriazine is a weak inhibitor of DHFR. Table 1 shows the list of compounds in the approval and investigational process against the DHFR target [15-17].

In one of the reviews, the therapeutic importance of sulfur compounds mostly, the sulfonyl or sulfonamide analogues were presented, which were found to have a broad range of activities from antimicrobial, anti-inflammatory, antiviral, anticonvulsant, antitubercular, antidiabetic, antileishmanial, carbonic anhydrase, anti-malarial, anticancer and others, etc. It has been proposed that these compounds can serve as good therapeutic agents against several fetal diseases [113]. Sulfadoxine is a sulfonamide pyrimidine targeting DHFR, while tosyl-D-proline and N-[Tosyl-D-Prolinyl]amino-ethanethiol are the $p$-toluenesulfonamides inhibiting TS.

The number of hybrid drugs with amine peroxide bridge was reported for tetraoxanes and trioxolanes (ozonides), which were found to be potent peroxidic anti-malarials. Among trioxolanes, arterolane was the first one that reached clinical trials but was withdrawn in phase 2 due to its stability issues. Artefenomel or OZ439 is another trioxolanes that have reached phase 3 of the clinical trials and have shown potent anti-plasmodial activity [114].
Moreover, OZ277 (RBx-1160) is in phase 3 trials, and its combination with piperaquine has also shown promising results. Peroxide-based molecules alone or as hybrid molecules could open up a new research area in the future as they are showing promising results, and few of them have entered the clinical stages [62]. Moreover, combinations of chlorproguanil hydrochloride dapsone-artesunate were designed as potent anti-malarial drugs, but they failed in phase 3 trials due to toxicity issues [62].

Acyclic nucleoside bisphosphonates were found to be inhibitors of the P. falciparum and showed anti-malarial activities [115]. Folate and nucleotide analogs are the two main categories of the TS enzyme. Inhibitors with fluorouracil $(5 \mathrm{FU})$ were the first of the TS inhibitor and were found to be antineoplastic agents. Six folate analogs of TS inhibitor are currently in clinical trials as AG337, raltitrexed, pemetrexed, nolatrexed, ZD9331, and GS7904L. Orotate analogs are found to be more selective towards parasites than uridine derivates. The most potent are precursors of the anticancer drug 5FU, 5-fluoro-orotic acid (5FO). Moreover, polyglutamate folates were found to be better substrates than monoglutamate. Two anticancer analogs with thymidine were tested as an anti-malarial TS, but activity was found to be poor [45]. Pyrimidine compound pralatrexate is a pteridine flucytosine analog that has shown antifungal activity. The active metabolites of tegafur (a combination of (1-(2-tetrahydrofuryl)-5-fluorouracil) and uracil), inhibits the enzyme thymidylate synthase (5-fluoro-deoxyuridinemonophosphate) and intercalate into RNA (5-fluorouridinetriphosphate). Tegafur is in the clinical trial, as shown in the table for cancer treatment [16]. Trifluridine, a fluorinated pyrimidine nucleoside, is an irreversible thymidylate synthase inhibitor and suppresses DNA synthesis. It is an antiviral drug for herpes simplex virus (HSV) infection [116]. 5,6-Dihydro-5-fluorouracil, also known as 5-fluorodihydrouracil, a hydropyrimidines has shown a cytotoxic activity in murine and human tumor cells that may in part be explainable by the reversible transformation to FU [117].

2,4-diamino-meta-diazine pharmacophore in diaminoantifolates is reported to be an important pharmacophore for DHFR inhibition. Inhibition of parasitic TS had been achieved using 5-fluoroorotate, thereby killing all malarial parasites; however, it was found to be toxic to the host due to 5-fluoropyrimidine incorporation into the nucleotide pool. It was also observed that when TS inhibitor as 1843 U89 was combined with thymidine it resulted in less toxicity to the host and was found to be selective for the parasite [118]. Tables 2 and 3 shows inhibitors in the approval and investigational phase with structures [15-17]. Pyrimethamine and P218 are antifolates, while ANX-510 (CoFactor) is a folatebased biomodulator drug. P218 was selective against bifunctional DHFR-TS of P. falciparum (PfDHFR-TS) and was found to be effective against drug-resistant mutants [119]. 
Leucovorin, a bio-modulator, and after chemical conversion becomes the active form of folate. It has also been reported that targeting PTR1 and DHFR-TS can lead to the development of potential drugs for Leishmaniasis. Two types of DHFR-TS inhibitors have been reported so far, the classical one, which resembles folic acid structure, and the non-classical, which are lipophilic antifolates lacking the glutamate sidechain. The series of class 5-benzyl-2,4-diaminopyridimines was reported to be the first inhibitor of DHFR against L. major 2,4-diaminoquinazolines was also reported as DHFR inhibitors against Trypanosoma and Leishmania. The DHFR-TS was found to be lethal to leishmania [120]. 2, 4 diaminopyrimidine derivatives were competitive inhibitors against recombinant enzymes LcPTR1 and LcDHFR [121]. It was found that 2,4 diaminopyrimidine derivatives are inhibitors of recombinant LcPTR1 and LcDHFR-TS lenzymes [121]. It has been established that a strong complex is formed by human TS and DHFR in vitro and they co-localize in the cytoplasm and nucleus of human normal and colon cancer cells [122]. For Cryptosporidiosis, effective treatments are required, as currently nitazoxanide, is moderately effective in children and not effective in AIDS patients. It is believed that nitazoxanide and paromomycin failure may be due to the fact that they don't kill parasites [123]. Hence, efforts are underway to find its potent and selective inhibitors. The selective inhibitor (2-amino-4-oxo-4,7-dihydropyrrolo[2,3-d]pyrimidin-methyl-phenyl-L-glutamic acid) for $C h$ TS was obtained, and X-ray structures with inhibitors were also resolved for human TS and ChTS, which helped further in the selectivity of compounds [124]. In another study, a thiol-substituted 2-hydroxy-N-phenylbenzamide was found to show good activity against $C h$ DHFRTS [22]. Methylenedioxyphenyl-aminophenoxypropanol analogues were discovered by virtual screening against ChTS [125]. More efforts are required in this direction, and perhaps already approved DHFR-TS inhibitors may also be effective against this parasite.

Several acid derivatives have been reported to inhibit DHFR and bifunctional DHFR-TS as well. Methotrexate (amethopterin), a glutamic acid, inhibits the DHFR resulting in the inhibition of purine nucleotide and TS [16]. Similarly, SP-722 is also a derivative of glutamic acid, while LY231514 is a pentacarboxylic acid derivative. LY341770 are compounds containing hippuric acid, in which a benzoyl group is linked to glycine [16]. Glutamic and hippuric acid derivatives have shown profound activities against DHFR$\mathrm{TS}$, and in the future, compounds from this class can prove to be effective in the treatment of various parasitic diseases. LY231514 and pemetrexed are the antifolate inhibitors of TS. LY231514 not only inhibits TS but also targets DHFR and is also referred to as multitargeted antifolate [126]. SP-876 is a hybrid peptide that links two different amino acids through a peptide bond. L-methionine (S)-S-oxide belongs to the class of compounds known as 1-alpha-amino acids, while mimosine (M) 2-amino-3-(3-hydroxy-4-oxo-1pyridinyl)propanoic acid is an alpha-amino acid. However, these drugs are in the investigational process, and their effectiveness is yet to be ascertained in clinical and pre-clinical trials.

It has been proposed that metformin and other biguanides could target folate metabolizing enzymes [127]. Chlorproguanil is a dichloro derivative of proguanil which is also known as chloroguanide and belongs to the class of 1-arylbiguanides. Trimethoprim, also known as proloprim is an anisoles compound. Gentamicin is a broad-spectrum aminoglycoside antibiotic. Sri-9662 belongs to the class pyrido[2,3-d] pyrimidines, while iclaprim is a novel diaminopyrimidine. N,O-Didansyl-L-tyrosine is a compound from the phenylalanine and derivatives class.

1,4-dithiothreitol are polyols, while pyridoxal phosphate is a pyridoxal derivative. N-pyridoxyl-glycine5-monophosphate belongs to pyridoxamine 5'-phosphate compounds. Artenimol is an artemisinin derivative. Pentamidine (diether) having pentane 1,5-diol with 4-amidinophenyl groups in place of both hydroxyl hydrogens.

Several TS inhibitors are currently in clinical trials as non-polyglutamylatable, antifolate analog ZD9331. The other most potent inhibitor of TS is GW1843U89, which is the benzoquinazoline compound [95]. Human cytosolic SHMT was found to be inhibited by antifolate lometrexol [44].

Pyrazolpyran derivatives were found to inhibit plant SHMT1; however, modelling studies have revealed that the compound can be a good target for SHMT, and for the first time, the crystallized structure of SHMT2 with lometrexol and pemetrexed was reported. It was concluded that they are potent inhibitors for both isoforms [44]. SHMT has gained a lot of importance as an anticancer target for the development of new drugs. Methotrexate and pemetrexed were crystallized with two isoforms of the SHMT plant. Hence, it has been suggested that antifolates can serve as SHMT inhibitors [128].

\section{COVID 19}

Pyrimethamine has also been found to possess antitumor activities. However, its target in cancer cells is still not clear, and it was observed that pyrimethamine could inhibit cancer cells of the lungs via DHFR. It was also observed that only pyrimethamine could also inhibit the epithelialmesenchymal transition (EMT), metastasis, and invasion of lung cancer cells. Hence, it can be concluded that the mechanism of pyrimethamine involves more than one target, not necessarily DHFR. It is believed that thymidine phosphorylase (TP) is closely associated with the EMT of 
cancer cells. It was concluded that pyrimethamine plays an act as a dual inhibitor by targeting DHFR and TP in a tumor [129]. In HIV-infected patients, pyrimethamine and leucovorin combination was more effective and safer as compared to trimethoprim/sulfamethoxazole in primary prophylaxis of Pneumocystis jiroveci pneumonia and Toxoplasma encephalitis [130].

The use of chloroquine/hydroxychloroquine in SARSCOV-2 patients has already been approved with a high risk of adverse effects [131, 132]. However, the use of these drugs in COVID-19 patients still requires further highquality clinical trials [133].

Fungal infections $P$. jirovecii pneumonia affects people with weak immune responses and, in some cases, are fatal. It results in asymptomatic lung colonization in normal people which may serve as carriers to spread it to immunocompromised individuals. It is considered a serious respiratory infection in AIDs patients. Its cases have declined due to prophylaxis and antiretroviral therapy. First-line prophylaxis treatment includes a combination treatment of dapsone, leucovorin, and pyrimethamine [134].

\section{Conclusion}

It is assessed that simultaneously using inhibitors for the two or three targets as DHFR, TS, and SHMT may be effective against several diseases. The aforementioned targets play a pivotal role in the folate pathway since the folate pathway is significant for the survival of many parasites. Hence it can be assessed that inhibition of these targets may be beneficial. For combating viral and protozoal infectious diseases, these targets in combination should be addressed. From the structural analysis of different organisms and SAR, it can be concluded that hybrid drugs may be designed for combating these targets simultaneously. The conserved regions of the enzymes can be utilized for this purpose. Structural elucidation can be utilized in the future for designing the drugs. These enzymes can be targeted against several diseases and can be assessed that these targets can play a significant role against a number of infectious diseases.

Supplementary Information The online version contains supplementary material available at https://doi.org/10.1007/s11033-022-07266-8.

Author contributions Contributed to the writing: HS and AZM.

Funding No funding available.

Data availability Not Available.

\section{Declarations}

Conflict of interest No competing of interest has been found.

Ethical approval Not Available.

Consent to participate Not Available.

Consent for publication Not Available.

\section{References}

1. Dikhit MR, Ansari MY, Sinha S, Ali V, Topno RK, Majhee JP et al (2018) Computational elucidation of novel antagonists and binding insights by structural and functional analyses of serine hydroxymethyltransferase and interaction with inhibitors. Gene Rep 10:17-25. https://doi.org/10.1016/j.genrep.2017.10.010

2. Lee SM, Kim MS, Hayat F, Shin D (2019) Recent advances in the discovery of novel antiprotozoal agents. Molecules 24(21):3886. https://doi.org/10.3390/molecules24213886

3. Yuthavong Y, Tarnchompoo B, Vilaivan T, Chitnumsub P, Kamchonwongpaisan S, Charman SA et al (2012) Malarial dihydrofolate reductase as a paradigm for drug development against a resistance-compromised target. Proc Natl Acad Sci U S A 109(42):16823-16828

4. Adina H, Laura K (2015) The molecular basis of antifolate resistance in Plasmodium falciparum: looking beyond point mutations. Ann N Y Acad Sci 1342(1):10-18

5. Shamshad H, Hafiz A, Althagafi II, Saeed M, Mirza AZ (2020) Characterization of the Trypanosoma brucei pteridine reductase active- site using computational docking and virtual screening techniques. Curr Comput Aided Drug Des 6(5):583-98. https:// doi.org/10.1080/15257770.2019.1615623

6. Cullia G, Tamborini L, Conti P, De Micheli C, Pinto A (2018) Folates in Trypanosoma brucei: achievements and opportunities. ChemMedChem 13(20):2150-2158

7. Nonaka H, Nakanishi Y, Kuno S, Ota T, Mochidome K, Saito Y et al (2019) Design strategy for serine hydroxymethyltransferase probes based on retro-aldol-type reaction. Nat Commun. https:// doi.org/10.1038/s41467-019-08833-7

8. Alessandro P, Angela T, Doug, Schirchd Giulia GM, Alessio LS, Fiascarellic Alessandra G, Bruno M et al (2016) Differential 3-bromopyruvate inhibition of cytosolic and mitochondrial human serine hydroxymethyltransferase isoforms, key enzymes in cancer metabolic reprogramming. Biochim Biophys ActaProteins Proteomics 1864(11):1506-17

9. Marani M, Paone A, Fiascarelli A, Macone A, Gargano M, Rinaldo S et al (2016) A pyrazolopyran derivative preferentially inhibits the activity of human cytosolic serine hydroxymethyltransferase and induces cell death in lung cancer cells. Oncotarget 7(4):4570-4583

10. Raphemot R, Lafuente-monasterio MJ, Gamo-benito FJ, Clardy J, Derbyshire R (2016) Discovery of dual-stage malaria inhibitors with new targets. Antimicrobial agents and chemotherapy 60(3):1430-1437

11. Ahyong V, Sheridan CM, Leon KE, Witchley JN, Diep J, Derisi JL (2016) Identification of Plasmodium falciparum specific translation inhibitors from the MMV malaria box using a high throughput in vitro translation screen. Malar J. https://doi.org/ 10.1186/s12936-016-1231-8

12. Jiang L, Lee PC, White J, Rathod PK (2000) Potent and selective activity of a combination of thymidine and 1843 U 89 , a 
folate-based thymidylate synthase inhibitor, against Plasmodium falciparum. Antimicrob Agents Chemother 44(4):1047-1050

13. Sopitthummakhun K, Thongpanchang C, Vilaivan T, Yuthavong Y, Chaiyen P, Leartsakulpanich U (2012) Plasmodium serine hydroxymethyltransferase as a potential anti-malarial target: inhibition studies using improved methods for enzyme production and assay. Malar J 11:1-12

14. Ledford H (2009) One drug, two targets. Antimalarial compound fights disease and fends off drug-resistant parasites in mice [Internet]. https://www.nature.com/articles/news.2009.353\#citeas Accessed from 8 Apr 2009

15. Pharmacorama (2020). https://www.pharmacorama.com. Accessed 21 Dec 2021

16. Drug Bank (2020). https://www.drugbank.ca. Accessed Oct 2021

17. U.S. Food and Drug Administration (USFDA) (2020). https:// www.fda.gov/

18. Yuvaniyama J, Chitnumsub P, Kamchonwongpaisan S, Vanichtanankul J, Sirawaraporn W, Taylor P et al (2003) Insights into antifolate resistance from malarial DHFR-TS structures. Nat Struct Biol 10(5):357-365

19. Furtado JM, Smith JR, Belfort R, Gattey D, Winthrop KL (2011) Toxoplasmosis: a global threat. J Glob Infect Dis 3(3):281-284

20. Hopper AT, Brockman Adam, Wise A, Gould J, Barks J, Radke JB et al (2019) Discovery of selective toxoplasma gondii dihydrofolate reductase inhibitors for the treatment of toxoplasmosis. J Med Chem 62(3):1562-76

21. Sumbria D, Singla LD (2019) Pharmacokinetics and pharmacology to drugs used for control of emerging cryptosporidiosis and toxoplasmosis in livestock and humans. J Entomol Zool Stud 7(2):1306-1313

22. Ruiz V, Czyzyk DJ, Valhondo M, Jorgensen WL, Anderson KS (2019) Novel allosteric covalent inhibitors of bifunctional Cryptosporidium hominis DHFR-TS from parasitic protozoa identified by virtual screening victor. Bioorg Med Chem Lett 29(11):1413-1418

23. Noorbakhsh F, Abdolmohammadi K, Fatahi Y, Dalili H, Rasoolinejad M, Rezaei F et al (2019) Zika virus infection, basic and clinical aspects: a review article. Iran J Public Health 48(1):20-31

24. Chen HR, Lai YC, Yeh TM (2018) Dengue virus non-structural protein 1: a pathogenic factor, therapeutic target, and vaccine candidate. J Biomed Sci 25(1):1-11

25. Simmons G, Rennekamp AJ, Chai N, Vandenberghe LH, Riley JL, Bates P (2003) Folatereceptor alpha and caveolae are not required for ebola virusglycoprotein-mediated viralinfection. $\mathbf{J}$ Virol 77(24):13433-13438

26. Chabner BA, Amrein PC, Druker BJ, Michaelson MD, Mitsiades CS, Goss PE et al (2006) Antineoplastic agents. In: Brunton LL, Lazo JS, Parker KL (eds) The Pharmacological basis of therapeutics, 11th edn. McGraw-Hill, New York, U.S.A., pp 1335-9

27. Beck S, Zhu Z, Oliveira MF, Smith DM, Rich JN, Bernatchez JA et al (2019) Mechanism of action of methotrexate against zika virus. Viruses 11(4):1-12

28. Fischer MA, Smith JL, Shum D, Stein DA, Parkins C, Bhinder B et al (2013) Flaviviruses are sensitive to inhibition of thymidine synthesis pathways. J Virol 87(17):9411-9419

29. Pascoalino BS, Courtemanche G, Cordeiro MT, Gil LHVG, Freitas-Junior LH (2016) Zika antiviral chemotherapy: identification of drugs and promising starting points for drug discovery from an FDA-approved library. F1000Research 5:2523

30. Saiz JC, Martín-Acebes MA (2017) The race to find antivirals for zika virus. Antimicrob Agents Chemother 61(6):1-9

31. Tonelli M, Naesens L, Gazzarrini S, Santucci M, Cichero E, Tasso B et al (2017) Host dihydrofolate reductase (DHFR)directed cycloguanil analogues endowed with activity against influenza virus and respiratory syncytial virus. Eur J Med Chem 135:467-78. https://doi.org/10.1016/j.ejmech.2017.04.070

32. Marois I, Cloutier A, Meunier I, Weingartl HM, Cantin AM, Richter MV (2014) Inhibition of influenza virus replication by targeting broad host cell pathways. PLoS ONE 9(10):1-11

33. Tonelli M, Naesens L, Gazzarrini S, Santucci M (2017) Host dihydrofolate reductase (DHFR)-directed cycloguanil analogues endowed with activity against influenza virus and respiratory syncytial virus Michele. Eur J Med Chem 135:467-478

34. Landi G, Linciano P, Borsari C, Bertolacini CP, Moraes CB, Cordeiro-Da-Silva A et al (2019) Structural Insights into the development of cycloguanil derivatives as Trypanosoma brucei pteridine-reductase-1 inhibitors. ACS Infect Dis 5(7):1105-1114

35. Wróbel A, Arciszewska K, Maliszewski D, Drozdowska D (2020) Trimethoprim and other nonclassical antifolates an excellent template for searching modifications of dihydrofolate reductase enzyme inhibitors. J Antibiot (Tokyo) 73(1):5-27. https://doi. org/10.1038/s41429-019-0240-6

36. Hew K, Dahlroth SL, Veerappan S, Pan LX, Cornvik T, Nordlund P (2015) Structure of the Varicella zoster virus thymidylate synthase establishes functional and structural similarities as the human enzyme and potentiates itself as a target of brivudine. PLoS ONE 10(12):1-16

37. Chen J, Zhang H, Chen X (2020) Pemetrexed inhibits Kaposi's sarcoma-associated herpesvirus replication through blocking dTMP synthesis. Antiviral Res 180:104825. https://doi.org/10. 1016/j.antiviral.2020.104825

38. Carmona-Martínez V, Ruiz-Alcaraz AJ, Vera M, Guirado A, Martínez-Esparza M, García-Peñarrubia P (2019) Therapeutic potential of pteridine derivatives: a comprehensive review. Med Res Rev 39(2):461-516

39. Balzarini JMR, de Clercq EDA (1991) Combinations of TSinhibitors and viral TKinhibitors in antiherpetic medicines. US5137724

40. Mesri EA, Cesarman E, Boshoff C (2010) Kaposi's sarcoma herpesvirus/ Human herpesvirus-8 (KSHV/HHV8), and the oncogenesis of Kaposi's sarcoma. Nat Rev Cancer 10(10):707-719

41. Maenpuen S, Sopitthummakhun K, Yuthavong Y, Chaiyen P, Leartsakulpanich U (2009) Characterization of Plasmodium falciparum serine hydroxymethyltransferase-a potential antimalarial target. Mol Biochem Parasitol 168(1):63-73

42. Asai A, Konno M, Koseki J, Taniguchi M, Vecchione A, Ishii H (2020) One-carbon metabolism for cancer diagnostic and therapeutic approaches. Cancer Lett 470:141-8. https://doi.org/10. 1016/j.canlet.2019.11.023

43. Raju A (2015) Dihydrofolate reductase as a versatile drug target in healthcare. J Proteins Proteomics 7(4):247-257

44. Scaletti E, Jemth AS, Helleday T, Stenmark P (2019) Structural basis of inhibition of the human serine hydroxymethyltransferase SHMT2 by antifolate drugs. FEBS Lett 593(14):1863-1873

45. Nzila A, Ward SA, Marsh K, Sims PFG, Hyde JE (2005) Comparative folate metabolism in humans and malaria parasites. Trends Parasitol 21(6):292-298

46. Cavazzuti A, Paglietti G, Hunter WN, Gamarro F, Piras S, Loriga $\mathrm{M}$ et al (2008) Discovery of potent pteridine reductase inhibitors to guide antiparasite drug development. Proc Natl Acad Sci U S A 105(5):1448-1453

47. Gibson MW, Dewar S, Ong HB, Sienkiewicz N, Fairlamb AH (2016) Trypanosoma brucei DHFR-TS revisited: characterisation of a bifunctional and highly unstable recombinant dihydrofolate reductase-thymidylate synthase. PLoS Negl Trop Dis 10(5):1-20

48. Sienkiewicz N, Jarosławski S, Wyllie S, Fairlamb AH (2008) Chemical and genetic validation of dihydrofolate reductasethymidylate synthase as a drug target in African trypanosomes. Mol Microbiol 69(2):520-533 
49. Marverti G, Ligabue A, Lombardi P, Ferrari S, Monti MG, Frassineti $C$ et al (2013) Modulation of the expression of folate cycle enzymes and polyamine metabolism by berberine in cisplatinsensitive and-resistant human ovarian cancer cells. Int J Oncol 43(4):1269-1280

50. Habtemariam S (2020) Recent advances in berberine inspired anticancer approaches: From drug combination to novel formulation technology and derivatization. Molecules 25(6):1426

51. Delfino RT, Santos-Filho OA, Figueroa-Villar JD (2002) Type 2 antifolates in the chemotherapy of falciparum malaria. J Braz Chem Soc 13(6):727-741

52. Valente M, Vidal AE, González-Pacanowska D (2019) Targeting kinetoplastid and apicomplexan thymidylate biosynthesis as an antiprotozoal strategy. Curr Med Chem 26(22):4262-79

53. Phadke S, Somani R, Pathak D (2020) New benzimidazole derivatives as inhibitors of pteridine reductase 1: design, molecular docking study and ADMET prediction. J Appl Pharm Sci 10(9):30-39

54. Teixeira BVF, Teles ALB, da Silva SG, Brito CCB, de Freitas HF, Pires ABL et al (2019) Dual and selective inhibitors of pteridine reductase 1 (PTR1) and dihydrofolate reductase-thymidylate synthase (DHFR-TS) from Leishmania chagasi. J Enzyme Inhib Med Chem 34(1):1439-1450

55. Dawson A, Gibellini F, Sienkiewicz N, Tulloch LB, Fyfe PK, McLuskey K et al (2006) Structure and reactivity of Trypanosoma brucei pteridine reductase: Inhibition by the archetypal antifolate methotrexate. Mol Microbiol 61(6):1457-1468

56. Osorio E, Aguilera C, Naranjo N, Marín M, Muskus C (2013) Biochemical characterization of the bifunctional enzyme dihydrofolate reductase-thymidylate synthase from Leishmania (Viannia) and its evaluation as a drug target. Biomedica 33(3):393-401

57. Corral MG, Haywood J, Stehl LH, Stubbs KA, Murcha MW, Mylne JS (2018) Targeting plant dihydrofolate reductase with antifolates and mechanisms for genetic resistance. Plant $\mathbf{J}$ 95(4):727-742

58. Montazeri M, Mehrzadi S, Sharif M, Sarvi S, Tanzifi A, Aghayan SA et al (2018) Drug resistance in toxoplasma gondii. Front Microbiol. https://doi.org/10.3389/fmicb.2018.02587

59. Schwertz G, Witschel MC, Rottmann M, Bonnert R, Leartsakulpanich U, Chitnumsub P et al (2017) antimalarial inhibitors targeting serine hydroxymethyltransferase (SHMT) with in vivo efficacy and analysis of their binding mode based on X-ray cocrystal structures. J Med Chem 60(12):4840-4860

60. Ducker GS, Ghergurovich JM, Mainolfi N, Suri V, Jeong SK, Li SHJ et al (2017) Human SHMT inhibitors reveal defective glycine import as a targetable metabolic vulnerability of diffuse large B-cell lymphoma. Proc Natl Acad Sci U S A 114(43):11404-11409

61. Schwertz G, Witschel MC, Rottmann M, Leartsakulpanich U, Chitnumsub P, Jaruwat A et al (2018) Potent inhibitors of plasmodial serine hydroxymethyltransferase (SHMT) featuring a spirocyclic scaffold. ChemMedChem 13(9):931-943

62. Muregi FW, Ishih A (2010) Next-generation antimalarial drugs: Hybrid molecules as a new strategy in drug design. Drug Dev Res 71(1):20-32

63. Sharma H, Landau MJ, Vargo MA, Spasov KA, Anderson KS (2013) First three-dimensional structure of toxoplasma gondii thymidylate synthase-dihydrofolate reductase: Insights for catalysis, interdomain interactions, and substrate channeling. Biochemistry 52(41):7305-7317

64. Schormann N, Senkovich O, Walker K, Wright DL, Anderson AC, Rosowsky A et al (2008) Structure-based approach to pharmacophore identification, in silico screening, and three-dimensional quantitative structure-activity relationship studies for inhibitors of Trypanosoma cruzi dihydrofolate reductase function. Proteins: Struct, Funct Genet 73:889-901

65. Sivaprakasam P, Tosso PN, Doerksen RJ (2009) Structure Activity relationship and comparative docking studies for cycloguanil analogs as PfDHFR-TS inhibitors. J Chem Inf Model 49(7):1787-1796

66. Sharma VK, Abbat S, Bharatam PV (2017) Pharmacoinformatic study on the selective inhibition of the protozoan dihydrofolate reductase enzymes. Mol Inform 36(11):1600156

67. Kamchonwongpaisan S, Charoensetakul N, Srisuwannaket C, Taweechai S, Rattanajak R, Vanichtanankul J et al (2020) Flexible diaminodihydrotriazine inhibitors of Plasmodium falciparum dihydrofolate reductase: Binding strengths, modes of binding and their antimalarial activities. Eur J Med Chem 195:112263. https://doi.org/10.1016/j.ejmech.2020.112263

68. Konstantinovic N, Guegan H, Stäjner T, Belaz S, Robert-Gangneux F (2019) Treatment of toxoplasmosis: current options and future perspectives. Food Waterborne Parasitol 15:e0036

69. Lapinskas PJ, Ben-Harari RR (2019) Perspective on current and emerging drugs in the treatment of acute and chronic toxoplasmosis. Postgrad Med 131(8):589-96. https://doi.org/10.1080/ 00325481.2019 .1655258

70. Welsch ME, Zhou J, Gao Y, Yan Y, Porter G, Agnihotri G et al (2016) Discovery of potent and selective leads against Toxoplasma gondii dihydrofolate reductase via structure-based design. ACS Med Chem Lett 7(12):1124-1129

71. Alday PH, Doggett JS (2017) Drugs in development for toxoplasmosis: advances, challenges, and current status. Drug Des Dev Ther 11:273-93

72. PDB. RCSB PDB, University of New Jersey. Department of Chemistry and Chemical Biology 610 Taylor Road. https://www. rcsb.org/

73. Chimera. Molecular graphics and analyses performed with UCSF Chimera, developed by the Resource for Biocomputing, Visualization, and Informatics at the University of California, San Francisco. University of California, San Francisco

74. BIOVIA Discovery Studio Visualizer, Drive Discovery with the Leading Molecular Graphics Environment

75. Atreya CE, Johnson EF, Irwin JJ, Dow A, Massimine KM, Coppens I, Stempliuk V et al (2003) A molecular docking strategy identifies Eosin B as a non-active site inhibitor of protozoal bifunctional thymidylate synthase- dihydrofolate reductase. J Biol Chem 278:14092-14100

76. Yuthavong Y, Yuvaniyama J, Chitnumsub P, Vanichtanankul J, Chusacultanachai S, Tarnchompoo B et al (2005) Malarial (Plasmodium falciparum) dihydrofolate reductase-thymidylate synthase: structural basis for antifolate resistance and development of effective inhibitors. Parasitology 130(3):249-259

77. Wan Q, Bennett BC, Wilson MA, Kovalevsky A, Langan P, Howell EE et al (2014) Toward resolving the catalytic mechanism of dihydrofolate reductase using neutron and ultrahighresolution X-ray crystallography. Proc Natl Acad Sci U S A 111(51):18225-18230

78. Sodolescu A, Dian C, Terradot L, Bouzhir-Sima L, Lestini R, Myllykallio H et al (2018) Structural and functional insight into serine hydroxymethyltransferase from Helicobacter pylori. PLoS ONE 13(12):1-23

79. Capelluto DGS, Hellman U, Cazzulo JJ, Cannata JJB (2000) Purification and some properties of serine hydroxymethyltransferase from Trypanosoma cruzi. Eur J Biochem 267(3):712-719

80. Mukherjee M, Sievers SA, Brown MT, Johnson PJ (2006) Identification and biochemical characterization of serine hydroxymethyl transferase in the hydrogenosome of Trichomonas vaginalis. Eukaryot Cell 5(12):2072-2078 
81. Rao NA, Ambili M, Jala VR, Subramanya HS, Savithri HS (2003) Structure-function relationship in serine hydroxymethyltransferase. Biochim Biophys Acta-Proteins Proteomics 1647(1-2):24-29

82. Tramonti A, Nardella C, di Salvo ML, Barile A, Cutruzzolà F, Contestabile R (2018) Human cytosolic and mitochondrial serine hydroxymethyltransferase isoforms in comparison: full kinetic characterization and substrate inhibition properties. Biochemistry 57(51):6984-6996

83. Paiardini A, Fiascarelli A, Rinaldo S, Daidone F, Giardina G, Koes DR et al (2015) Screening and in vitro testing of antifolate inhibitors of human cytosolic serine hydroxymethyltransferase. ChemMedChem 10(3):490-497

84. Pornthanakasem W, Kongkasuriyachai D, Uthaipibull C, Yuthavong Y, Leartsakulpanich U (2012) Plasmodium serine hydroxymethyltransferase: indispensability and display of distinct localization. Malar J. 11(m):1-9

85. Leartsakulpanich U, Kongkasuriyachai D, Imwong M, Chotivanich K, Yuthavong Y (2008) Cloning and characterization of Plasmodium vivax serine hydroxymethyltransferase. Parasitol Int 57:223-228

86. Chitnumsub P, Ittarat W, Jaruwat A, Noytanom K, Amornwatcharapong W, Pornthanakasem W et al (2014) The structure of Plasmodium falciparum serine hydroxymethyltransferase reveals a novel redox switch that regulates its activities. Acta Crystallogr Sect D Biol Crystallogr 70(6):1517-1527

87. Li X, Yang J, Pu Q, Peng X, Xu L, Liu S (2019) Serine hydroxymethyltransferase controls blood-meal digestion in the midgut of Aedes aegypti mosquitoes. Parasites and Vectors 12(1):1-15. https://doi.org/10.1186/s13071-019-3714-2

88. Hadni H, Elhallaoui M (2019) Molecular docking and QSAR studies for modeling the antimalarial activity of hybrids 4-anilinoquinoline-triazines derivatives with the wild-type and mutant receptor pf-DHFR. Heliyon 5(8):2357. https://doi.org/10.1016/j. heliyon.2019.e02357

89. Amornwatcharapong W, Maenpuen S, Chitnumsub P, Leartsakulpanich U, Chaiyen P (2017) Human and plasmodium serine hydroxymethyltransferases differ in rate-limiting steps and $\mathrm{pH}$ dependent substrate inhibition behavior. Arch Biochem Biophys 630:91-100. https://doi.org/10.1016/j.abb.2017.07.017

90. Franca TCC, Wilter A, Ramalho TC, Pascutti PG, FigueroaVillar JD (2006) Molecular dynamics of the interaction of Plasmodium falciparum and human serine hydroxymethyltransferase with 5-formyl-6-hydrofolic acid analogues: design of new potential antimalarials. J Braz Chem Soc 17(7):1383-1392

91. Arooj M, Sakkiah S, Cao GP, Lee KW (2013) An innovative strategy for dual inhibitor design and its application in dual inhibition of human thymidylate synthase and dihydrofolate reductase enzymes. PLoS One 8(4):e60470

92. Sharma M, Chauhan K, Shivahare R, Vishwakarma P, Suthar MK, Sharma A et al (2013) Discovery of a new class of natural product-inspired quinazolinone hybrid as potent antileishmanial agents. J Med Chem 56(11):4374-4392

93. Radwan AA, Alanazi FK (2020) Biological activity of quinazolinones. https://doi.org/10.5772/intechopen.85315

94. Tarosh SP, Jaimin DB, Ritu BD, Chaitanya JC, Bhavesh DP, Bharat CD (2019) Design and synthesis of leucine-linked quinazoline-4(3H)-one-sulphonamide molecules distorting malarial reductase activity in the folate pathway. Arch Pharm (Weinheim) 352(9):e1900099. https://doi.org/10.1002/ardp.201900099

95. Chu E, Gollerkeri A (2002) Resistance to inhibitor compounds of thymidylate synthase. Encycl Cancer 4:107-113

96. Beutel G, Glen H, Schöffski P, Chick J, Gill S, Cassidy J et al (2005) Phase I study of OSI-7904L, a novel liposomal thymidylate synthase inhibitor in patients with refractory solid tumors. Clin Cancer Res 11(15):5487-5495

97. Sharma PC, Kaur G, Pahwa R, Sharma A, Rajak H (2011) Quinazolinone analogs as potential therapeutic agents. Curr Med Chem 18(31):4786-812

98. Kennewell PD (2007) 1.03-Major drug introductions. Comprehensive medicinal chemistry II, 1st edn. Elsevier Ltd., Amsterdam, pp 97-249

99. Carmen AJ, Carlos M (2008) Antimetabolites. Medicinal chemistry of anticancer drugs. Elsevier Inc., Amsterdam, pp 9-52

100. Abdul H, Mariya A-R, Maliha U, Syed Abid A, Arshia Marium I et al (2018) Quinazoline and quinazolinone as important medicinal scaffolds: a comparative patent review (2011-2016). Expert Opin Ther Pat 28(4):281-97

101. Alagarsamy V, Chitra K, Saravanan G, Solomon VR, Sulthana MT, Narendhar B (2018) An overview of quinazolines: pharmacological significance and recent developments. Eur J Med Chem 151:628-685. https://doi.org/10.1016/j.ejmech.2018.03.076

102. Dhaval BP, Kfcrzainjal DP, Neelam PP, Krupa RP, Dhanji PR, Smita DR, Naumita SS, Devendra DZ, Hitesh DP (2019) Design, synthesis, and biological and in silico study of fluorine-containing quinoline hybrid thiosemicarbazide analogues. J Heterocyclic Chem 56(8):2235-2252

103. Tripathi M, Taylor D, Khan SI, Tekwani BL, Ponnan P, Das US et al (2019) Hybridization of fluoro-amodiaquine (FAQ) with pyrimidines: synthesis and antimalarial efficacy of FAQ-pyrimidines. ACS Med Chem Lett 10(5):714-719

104. Raimondi MV, Randazzo O, La FM, Barone G, Vignoni E, Rossi D et al (2019) DHFR inhibitors: reading the past for discovering novel anticancer agents. Molecules 24(6):1-19

105. Wang F, Zhang G, Zang C, Pan H, Ma L, Li C et al (2019) Preparation and in vitro/vivo evaluation of nano-liposomal form of febrifugine hydrochloride. J Nanosci Nanotechnol 20(4):2558-2566

106. Kikuchi H, Tasaka H, Hirai S, Takaya Y, Iwabuchi Y, Ooi H et al (2002) Potent antimalarial febrifugine analogues against the Plasmodium malaria parasite. J Med Chem 45(12):2563-2570

107. Secrieru A, Costa ICC, O'Neill PM, Cristiano MLS (2020) Antimalarial agents as therapeutic tools against toxoplasmosis-a short bridge between two distant illnesses. Molecules 25:1574

108. Nqoro X, Tobeka N, Aderibigbe BA (2017) Quinoline-based hybrid compounds with antimalarial activity. Molecules 22(12):22668

109. Araújo NCP, Barton V, Jones M, Stocks PA, Ward SA, Davies J et al (2009) Semi-synthetic and synthetic 1,2,4-trioxaquines and 1,2,4-trioxolaquines: synthesis, preliminary SAR and comparison with acridine endoperoxide conjugates. Bioorganic Med Chem Lett 19(7):2038-43. https://doi.org/10.1016/j.bmcl.2009.02.013

110. Adhikari N, Kashyap A, Shakya A, Ghosh SK, Bhattacharyya DR, Bhat HR et al (2020) Microwave assisted synthesis, docking and antimalarial evaluation of hybrid PABA-substituted 1,3,5-triazine derivatives. J Heterocycl Chem 57:2389-99

111. Chopra R, Singh L, Chibale K, Singh K (2019) Synthesis, in silico molecular docking, ADME evaluation and in vitro antiplasmodial activity of pyrimidine-based hybrid molecules. ChemistrySelect 4(43):12556-12558

112. Sahu S, Ghosh SK, Gahtori P, Pratap Singh U, Bhattacharyya DR, Bhat HR (2019) In silico ADMET study, docking, synthesis and antimalarial evaluation of thiazole-1,3,5-triazine derivatives as Pf-DHFR inhibitor. Pharmacol Rep 71(5):762-7. https://doi. org/10.1016/j.pharep.2019.04.006

113. Zhao C, Rakesh KP, Ravidar L, Fang WY, Qin HL (2019) Pharmaceutical and medicinal significance of sulfur (SVI)-Containing motifs for drug discovery: a critical review. Eur J Med Chem 162:679-734. https://doi.org/10.1016/j.ejmech.2018.11.017 
114. Tiwari MK, Yadav DK, Chaudhary S (2019) Recent developments in natural product inspired synthetic 1,2,4- trioxolanes (ozonides): an unusual entry into antimalarial chemotherapy. Curr Top Med Chem 19(10):831-846

115. Špaček P, Keough DT, Chavchich M, Dračínský M, Janeba Z, Naesens L et al (2017) Synthesis and evaluation of symmetric acyclic nucleoside bisphosphonates as inhibitors of the Plasmodium falciparum, Plasmodium vivax and human 6-oxopurine phosphoribosyltransferases and the antimalarial activity of their prodrugs. Bioorganic Med Chem 25(15):4008-4030

116. Van Cutsem E, Danielewicz I, Saunders MP, Pfeiffer P, Argilés G, Borg C et al (2020) Trifluridine/tipiracil plus bevacizumab in patients with untreated metastatic colorectal cancer ineligible for intensive therapy: the randomized TASCO1 study. Ann Oncol 31(9):1160-8. https://doi.org/10.1016/j.annonc.2020.05.024

117. LaFrate AL, Katzenellenbogen JA (2007) Improved chemical syntheses of 5,6-dihydro-5-fluorouracil. J Org Chem 72(22):8573-8576

118. Muraleedharan KM, Avery MA (2006) Advances in the discovery of new antimalarials. Comprehensive medicinal chemistry II. Elsevier, Amsterdam, pp 765-814

119. Chughlay MF, Rossignol E, Donini C, El Gaaloul M, Lorch U, Coates S, Langdon G, Hammond T, Möhrle J, Chalon S et al (2020) First-in-human clinical trial to assess the safety, tolerability and pharmacokinetics of P218, a novel candidate for malaria chemoprotection. Br J Clin Pharmacol 86:1113-24

120. Das Neves GMH, Kagami LP, Gonçalves IL, Eifler-Lima VL (2019) Targeting pteridine reductase 1 and dihydrofolate reductase: the old is a new trend for leishmaniasis drug discovery. Futur Med Chem 11(16):207-2130

121. Teixeira BVF, Teles ALB, da Silva SG, Brito CCB, de Freitas HF, Pires ABL et al (2019) Dual and selective inhibitors of pteridine reductase 1 (PTR1) and dihydrofolate reductase-thymidylate synthase (DHFR-TS) from leishmania chagasi. J Enzyme Inhib Med Chem 34(1):1439-50. https://doi.org/10.1080/14756366. 2019.1651311

122. Antosiewicz A, Jarmuła A, Przybylska D, Mosieniak G, Szczepanowska J, Kowalkowska A et al (2017) Human dihydrofolate reductase and thymidylate synthase form a complex in vitro and co-localize in normal and cancer cells. J Biomol Struct Dyn 35(7):1474-90. https://doi.org/10.1080/07391102.2016.1186560

123. Jumani RS, Bessoff K, Love MS, Miller P, Stebbins EE, Teixeira JE et al (2018) A novel piperazine-based drug lead for cryptosporidiosis from the medicines for malaria venture open-access malaria box. Antimicrob Agents Chemother 62(4):1-15

124. Czyzyk DJ, Valhondo M, Deiana L, Tirado-Rives J, Jorgensen WL, Anderson KS (2019) Structure activity relationship towards design of cryptosporidium specific thymidylate synthase inhibitors. Eur J Med Chem 183:111673. https://doi.org/10.1016/j. ejmech.2019.111673

125. Ruiz VG, Czyzyk DJ, Kumar VP, Jorgensen WL, Anderson KS (2020) Targeting the TS dimer interface in bifunctional Cryptosporidium hominis DHFR-TS from parasitic protozoa: virtual screening identifies novel TS allosteric inhibitors. Bioorganic Med Chem Lett 30(16):127292. https://doi.org/10.1016/j.bmcl. 2020.127292

126. Chu E, Callender MA, Farrell MP, Schmitz JC (2003) Thymidylate synthase inhibitors as anticancer agents: from bench to bedside. Cancer Chemother Pharmacol Suppl 52(1):80-89

127. Gabel SA, Duff MR, Pedersen LC, DeRose EF, Krahn JM, Howell EE et al (2017) A structural basis for biguanide activity. Biochemistry 56(36):4786-4798

128. Ruszkowski M, Sekula B, Ruszkowska A, Contestabile R, Nogues I, Angelaccio S et al (2019) Structural basis of methotrexate and pemetrexed action on serine hydroxymethyltransferases revealed using plant models. Sci Rep 9(1):1-14

129. Liu H, Qin Y, Zhai D, Zhang Q, Gu J, Tang Y et al (2019) Antimalarial drug pyrimethamine plays a dual role in antitumor proliferation and metastasis through targeting DHFR and TP. Mol Cancer Ther 18(3):541-555

130. Valcarce N, Alvarez H, Mariño AI, Casás A, Montero AM, Rodríguez I (2016) Prevention of toxoplasmic encephalitis and pneumocystis jiroveci pneumonia in patients infected with HIV: efficacy and safety of dapsone/pyrimethamine/leucovorin. Eur J Hosp Pharm 23(Suppl 1):A1-A262

131. Mandy P (2020) Chloroquine and hydroxychloroquine: current evidence for their effectiveness in treating COVID-19 - a laysummary. HealthSense. Accessed 30 Nov 2021

132. Mirza AZ, Shamshad H, Abdulrhman F, Habeebullah TM (2021) An overview of viruses discovered over the last decades and drug development for the current pandemic. Eur J Pharmacol 890(173746):1-13. https://doi.org/10.1016/j.ejphar.2020.173746

133. Hashem AM, Alghamdi BS, Algaissi AA, Alshehri FS (2020) Therapeutic use of chloroquine and hydroxychloroquine in COVID-19 and other viral infections: a narrative review. Travel Med Infect Dis. https://doi.org/10.1016/j.tmaid.2020.101735

134. Mbabazi E, Uthman OA, Young T (2017) Optimal timing for discontinuation of Pneumocystis jiroveci pneumonia prophylaxis in adult patients on highly active antiretroviral therapy (HAART) for HIV infection. Cochrane Database Syst Rev 2017(1):1-3

Publisher's Note Springer Nature remains neutral with regard to jurisdictional claims in published maps and institutional affiliations. 